NBER WORKING PAPER SERIES

\title{
SOCIAL TRANSMISSION BIAS AND INVESTOR BEHAVIOR
}

\author{
Bing Han \\ David Hirshleifer \\ Johan Walden \\ Working Paper 24281 \\ http://www.nber.org/papers/w24281 \\ NATIONAL BUREAU OF ECONOMIC RESEARCH \\ 1050 Massachusetts Avenue \\ Cambridge MA 02138 \\ February 2018, Revised January 2020
}

A previous version of this paper was entitled, "Self-Enhancing Transmission Bias and Active Investing." We thank seminar participants at Cambridge University, Central University of Finance and Economics, Chinese University of Hong Kong, Columbia University, Emory University, the Federal Reserve Board of New York, Nanyang Business School, National University of Singapore, New York University, Oxford University, Princeton University, Shanghai Advanced Institute of Finance, Singapore Management University, Southwestern University of Finance and Economics, UCLA, UCSD, University of Hong Kong, University of North Carolina, University of Toronto, University of Washington at Seattle, Washington University in St. Louis, Xiamen University, Yale University, and the Institute for Mathematical Behavioral Sciences at UC Irvine; participants at the National Bureau of Economic Research behavioral finance working group meeting in Chicago, the American Finance Association annual meetings, the Applied Behavioral Finance Conference at UCLA, the Linde Conference at Caltech, the BYU Red Rock Finance Conference, the SITE conference at Stanford University, and the 2nd China International Forum on Finance and Policy; Jennifer Conrad (Editor), an anonymous referee, the NBER discussant, Nick Barberis; the AFA discussant, Blake LeBaron; the ABF discussant, Andrea Eisfeldt; the Five Star discussant JuanJuan Meng; Markus Brunnermeier, Terry Burnham, Jean-Paul Carvalho, David Dicks, Jakub Jurek, Edward Rice, Nikolai Roussanov, Martin Schmalz, Siew Hong Teoh, Paul Tetlock, Rossen Valkanov, Michela Verardo, Ivo Welch, Jeff Wurgler, Hongjun Yan, Liyan Yang, and Wei Xiong for very helpful comments; and Jason Chan, SuJung Choi, and Major Coleman for helpful research assistance. The views expressed herein are those of the authors and do not necessarily reflect the views of the National Bureau of Economic Research.

NBER working papers are circulated for discussion and comment purposes. They have not been peerreviewed or been subject to the review by the NBER Board of Directors that accompanies official NBER publications.

(C) 2018 by Bing Han, David Hirshleifer, and Johan Walden. All rights reserved. Short sections of text, not to exceed two paragraphs, may be quoted without explicit permission provided that full credit, including (C) notice, is given to the source. 
Social Transmission Bias and Investor Behavior

Bing Han, David Hirshleifer, and Johan Walden

NBER Working Paper No. 24281

February 2018, Revised January 2020

JEL No. D03,D83,D85,D9,D91,G02,G11,G12,G14,G4,G41

\section{ABSTRACT}

We offer a new social approach to investment decision making and asset prices. Investors discuss their strategies and convert others to their strategies with a probability that increases in investment returns. The conversion rate is shown to be convex in realized returns. Unconditionally, active strategies (e.g., high variance and skewness) dominate, although investors have no inherent preference over these characteristics. The model has strong predictions for how adoption of active strategies depends on investors' social networks. In contrast with nonsocial approaches, sociability, self-enhancing transmission and other features of the communication process determine the popularity and pricing of active investment strategies.

Bing Han

Department of Finance

Rotman School of Management

University of Toronto

105 St. George Street

Toronto, Ontario

Canada

Bing.Han@Rotman.Utoronto.Ca

David Hirshleifer

The Paul Merage School of Business

University of California, Irvine

4291 Pereira Drive

Irvine, CA 92697

and NBER

david.h@uci.edu
Johan Walden

Haas School of Business

University of California at Berkeley

545 Student services building, \#1900

Berkeley, CA 94720

walden@ haas.berkeley.edu 


\section{Introduction}

A neglected topic in financial economics is how investment ideas are transmitted from person to person. In most investments models, the influence of individual choices on others is mediated by price or by quantities traded in impersonal markets. However, more direct forms of social interaction also affect investment decisions. As Shiller (1989) put it, "...Investing in speculative assets is a social activity. Investors spend a substantial part of their leisure time discussing investments, reading about investments, or gossiping about others' successes or failures in investing." In one survey, individual investors were asked what first drew their attention to the firm whose stock they had most recently bought. Almost all referred to direct personal contact; personal interaction was also important for institutional investors (Shiller and Pound 1989). Furthermore, an empirical literature finds that social interactions affect investment decisions by individuals and money managers, including selection of individual stocks. ${ }^{1}$

We offer a new social approach to the theory of investor behavior by modeling how the process by which ideas are transmitted affects trading strategies. We explore how biases in conversation promote superficially-appealing personal investing strategies, focusing on active versus passive investment behavior in security markets. Our goal is to provide an integrated explanation for several well-known puzzles and stylized facts in the literature while providing new insights and empirical implications.

Notably, individual investors trade actively and have invested in active investment funds for decades, and thereby have on average underperformed net of costs relative to a passive strategy such as holding a market index - the active investing puzzle. ${ }^{2}$ Second is the underdiversification puzzle, that investors hold individual stocks and active funds, thereby

\footnotetext{
${ }^{1}$ Shiller $(2000,2017)$ discusses other indications that conversation matters for security investment decisions. The empirical literature includes Kelly and O'Grada (2000), Duflo and Saez (2002, 2003), Hong, Kubik, and Stein (2004, 2005), Massa and Simonov (2005), Ivković and Weisbenner (2007), Brown et al. (2008), Cohen, Frazzini and Malloy (2008, 2010), Shive (2010), Gray, Crawford, and Kern (2012), and Mitton, Vorkink, and Wright (2018).

${ }^{2}$ On underperformance in individual trading, see Barber and Odean (2000a), Barber et al. (2009). Carhart (1997) and Daniel et al. (1997) find that active funds typically do not outperform the returns of passive benchmarks. French (2008) documents very large fees paid in the aggregate by investors to active funds. In recent years there has also been a shift from active mutual funds toward both indexing but also to hedge funds. In any case, what is notable is how slow has been the shift from active funds toward indexing over a period of decades.
} 
increasing portfolio volatility without adequate compensating mean returns. For example, the idiosyncratic risk exposure of Swedish households accounts for half of the return variance for the median household (Calvet, Campbell, and Sodini 2007). Third, individual investors are attracted to stocks with high skewness - so-called lottery stocks - see Kumar (2009), Bali, Cakici, and Whitelaw (2011), Han and Kumar (2013), and Boyer and Vorkink (2014). This behavior is not consistent with standard investor preferences. A final feature of investor behavior is that flows into funds are a convex function of past performance (Chevalier and Ellison 1997; Sirri and Tufano 1998).

The leading explanations typically focus on a subset of these puzzles and stylized facts, and do not address other dimensions of investor behavior. Naive active investing, for example, has been explained by individual-level cognitive biases. Excessive individual investor trading is typically attributed to investor overconfidence (DeBondt and Thaler 1995; Barber and Odean 2000a), the tendency of investors to overestimate their abilities. However, there is also evidence that trading aggressiveness is greatly exacerbated by social interactions, a fact that is not emphasized by this literature. ${ }^{3}$

Standard explanations for underdiversification include hedging motives and heterogeneous preferences, but several studies highlight the limitations of these explanations. Massa and Simonov (2006) find that hedging motives for human capital risk, which is a fundamental source of individual investor risk, does not explain heterogeneous investment behavior among individual investors well. Similarly, Calvet, Campbell and Sodini $(2007,2009)$ find that rational diversification and portfolio rebalancing motives do not suffice to explain investors' portfolio holdings well.

The leading explanations for the attraction of investors to lottery stocks have been based on individual-level biases, and specifically on nontraditional preferences (Brunnermeier and Parker 2005; Barberis and Huang 2008). Such explanations do not, however, explain why higher intensity of social interactions is associated with stronger attraction of investors to both high volatility and high skewness stocks, where this intensity is proxied by population

\footnotetext{
${ }^{3}$ For example, participants in investment clubs seem to select individual stocks based on reasons that are easily exchanged with others (Barber, Heath, and Odean 2003); select small, high-beta, growth stocks; turn over their portfolios very frequently; and underperform the market (Barber and Odean 2000b). There is evidence (mentioned in footnote 1) that stock picking by individuals and institutions, an active investing behavior, spreads socially, and that stock market participation increases with measures of social connectedness (Hong, Kubik, and Stein 2004; Kaustia and Knüpfer 2012). Furthermore, during the millennial high-tech boom, investors who switched early to online trading (and who were probably early participants in online forms of social interaction) subsequently began to trade more actively and speculatively, and earned reduced trading profits (Barber and Odean 2002; Choi, Laibson, and Metrick 2002).
} 
density (Kumar 2009). Bali et al. (2019) find that lottery stocks are more overpriced when there is greater intensity of social interactions, where the intensity is proxied by either population density or the Social Connectedness Index from Facebook.

Huang, Wei, and Yan (2007) propose that the convexity of fund flow as a function of performance derives from a combination of investor participation costs and learning about fund managers' ability from past returns. Our approach differs in focusing on the effects of social interaction on investor decisions.

This paper offers a unified framework based upon social interactions that addresses all of these stylized facts, and also provides several novel testable empirical implications at both the aggregate and individual investor level. In our model, investors adopt either an Active $(A)$ or Passive $(P)$ investment strategy. We interpret $A$ as the riskier option, measured by volatility and/or skewness. Investors transmit information about strategy performance amongst each other and suffer systematic biases in the transmission process that end up promoting active over passive investing.

Key features of the transmission process are the sending and receiving schedules. The sending schedule gives the probability that the sender reports their return outcome as a function of that return; and the receiving schedule gives the probability that a given reported return will convert the receiver to the strategy of the sender. Investors like to recount to others their investment victories more than their defeats. We call this sender behavior self-enhancing transmission bias, or SET. We discuss the considerable evidence suggesting that self-enhancing thought processes influence financial behavior.

Receivers do not fully discount for SET. The unified psychological underpinning of our premises that receivers neglect selection bias in the reports they receive, and overextrapolate performance reports, is the representativeness heuristic of (Tversky and Kahneman 1974). The representativeness heuristic implies that investors (such as receivers) take small samples of performance as highly representative of the underlying return process, resulting in both overextrapolation of returns, and neglect of the selection bias toward reports of high returns. Motivated by the psychology of salience, we also make a second key psychological assumption, that receivers attend more to extreme outcomes.

We use these assumptions to analyze the interplay between the return distributions of investment strategies and investor sending and receiving schedules. This interplay determines which investment strategies spread through the population. We find that the 
relation between a strategy's past returns and the conversion rate to that strategy is in general convex, as documented in Kaustia and Knüpfer (2012). Furthermore, the degree of convexity as determined by empirically measurable parameters of the social interaction process. These results about the convexity of flows as a function of past returns provide our first contribution.

We also study the aggregate evolutionary outcome without conditioning upon returns. We find that high volatility increases the fraction of investors who follow the active strategy, because senders tend to report high returns more often than low returns (i.e., there is SET). Receivers do not fully discount for the biased sample of return reports they receive, and naively think that past performance is indicative of future performance. Higher volatility intensifies the effect of the selection bias toward high reports. The tendency for high volatility strategies to spread is further reinforced to the extent that investors are highly attentive to extremes.

Moreover, we show that high skewness strategies tend to spread - even after controlling for volatility. The survival advantage of positively skewed strategies comes from the fact that they more often generate extreme high returns, which in turn are most often reported and attended to.

The attraction of investors to high variance and high skewness (lottery) stocks tends to place an upward pressure on price, and can therefore induce return anomalies. The model therefore offers an explanation for the overvaluation of volatile or lottery-like categories of stocks, such as growth stocks, distressed firms, firms that have recently undertaken Initial Public Offerings (IPOs), and high volatility and high beta firms; and heavy trading and overvaluation of firms that are attractive as topics of conversation (such as sports, entertainment, and media firms, firms with hot consumer products, and local firms). So active investment strategies tend to spread through the population even if they suffer from a return penalty - lower expected returns than passive investment strategies - so long as the penalty is not too large.

Our findings that greater volatility and skewness encourage the spread of an investment strategy, and that such strategies tend to spread even when they are subject to return penalties, provide the second, third, and fourth key contributions of this paper, respectively. There are alternative theories based upon individual-level biases that offer piecemeal explanations for subsets of these aforementioned puzzles. In contrast, our framework 
provides a unified explanation, as well as an extensive set of further empirical implications.

A further key implication of our analysis is that the effects described above are stronger when the intensity of social interactions is greater. This provides a set of distinctive empirical implications about the effects of the communication process between investors about the performance of their investment strategies. There is evidence supporting the hypothesis that these effects are associated with proxies for sociability. ${ }^{4}$ For example, in our model greater sociability increases the slope and convexity of the transformation schedule describing the adoption of the active investing strategy as a function of its past returns. More generally, our framework offers several further testable implications deriving from comparative statics on the parameters of sending and receiving schedules, which we jointly refer to as communicability parameters. These include parameters for the strength of SET in senders' messaging about returns, and for the sensitivity of receivers to such return reports. The predictions about how communicability affects the aggregate spread of active strategies provides our fifth contribution.

A natural extension of our model that embeds investors in a social network generates various novel predictions about the behaviors of individual investors. We show that the strategy an investor adopts depends on who the investor is connected to, the performance, volatilities and skewnesses of network neighbors' strategies, and the investors' sociability. These investor-specific predictions provide our sixth key contribution.

We are not the first to examine biases in the social transmission of behavior. Economists have modeled how cultural evolutionary processes affect ethnic and religious traits, and altruistic preferences Bisin and Verdier (2000, 2001). Financial models have examined how social interactions affect information aggregation, trading and prices. ${ }^{5}$ Our paper differs from this literature in examining how social transmission biases such as SET affect the social evolutionary outcome.

DeMarzo, Vayanos, and Zwiebel (2003) show that persuasion bias, the failure of receivers to account for possible repetition in the messages they hear from others, plays an important

\footnotetext{
${ }^{4}$ See, e.g., Hong, Kubik, and Stein (2004) and Kaustia and Knüpfer (2012) for stock market participation, and Kumar (2009) for preference for high skewness stocks and high volatility stocks.

${ }^{5}$ Such models address how information flows in social networks affect asset markets (DeMarzo, Vayanos, and Zwiebel 2001), crises and herd behavior (Cipriani and Guarino (2002, 2008)), IPO allocations and pricing (Welch 1992), as well as information acquisition, liquidity and trading volume (Özsöylev and Walden 2011; Han and Yang 2013). Burnside, Eichenbaum, and Rebelo (2016) apply an epidemic model to explain booms and busts in the housing market; they do not examine transmission bias in conversation, which is the focus of our paper.
} 
role in the process of social opinion formation. Our paper differs in focusing on other types of transmission biases - biases in what messages are sent, and in how they are interpreted; and in exploring the spread of active investing. Hong, Kubik, and Stein (2004) provide evidence that individuals who are more social participate more in stock market. However, in principle social interaction could cause contagion of nonparticipation (e.g., people could spread negative attitudes to others). Our paper examines explicitly whether it is favorable or unfavorable information that is transmitted and used by others, and more generally whether active or passive investing strategies spread. ${ }^{6}$

\section{The Economic Setting}

In this section, we discuss the psychological and social underpinnings of our approach to viewing investment behavior as a process of "messages" being sent and influencing receivers in the investor population. We capture this process formally by making technical assumptions about sending and receiving behavior among investors and, in the second part of the section, introduce a dynamic model with many investors in an economy.

\subsection{Underpinnings of Approach}

Our starting point is that investors experience self-enhancing transmission bias (SET). In particular, an investor experiencing a high return likes to report this to others, i.e., the probability of reporting returns to others is increasing in these returns.

There are good rational reasons for such behavior, though it can also be reinforced by psychological bias. It is, for example, natural if investors like to report-i.e., send messages about - high returns. In a review of the impression management field, Leary and Kowalski (1990) discuss how people tend to avoid lying, but, consistent with SET, selectively omit information "... to put the best parts of oneself into public view" (pp. 40-1).

There is substantial evidence of SET in financial settings. For example, consistent with SET, in a Facebook-style social network for individual investors, Heimer and Simon (2015) report that the frequency with which an investor contacts other traders in a given week is increasing in the investor's short-term return. In empirical work developed after

\footnotetext{
${ }^{6}$ Also, in Hong, Kubik, and Stein (2004), the knowledge and practices that social investors disproportionately acquire are useful. In contrast, our approach implies that more social investors will make better decisions in some ways (e.g., participation) but worse decisions other ways (e.g., uninformed stock picking or day trading).
} 
this paper, Ammann and Schaub (2016) find strong evidence that posting by traders on an online social trading platform, often about their own strategies, is increasing with the performance of their trading strategies. Escobar and Pedraza (2019) find based on random assignment of students across classrooms in a financial education initiative that individuals share their most successful investing experiences, encouraging unprofitable stock trading among peers. Lim, Ng, and Uzzi (2020) find that professional investors report their high returns more than their low returns to others in instant messages. Furthermore, people tend to direct greater attention to their high return experiences; Scandinavian and U.S. investors reexamine their portfolios more frequently when the market has risen than when it has declined (Karlsson, Loewenstein, and Seppi (2009) and Sicherman et al. (2012)). Huang, Hwang, and Lou (2018) provide evidence of SET in investor communication about firms in different industries. Consistent with SET, for a wide set of consumer products, positive word-of-mouth discussion of user experiences tends to predominate over negative discussion (see the review of East, Hammond, and Wright (2007)), perhaps because users want to persuade others that they are expert at product choice (Wojnicki and Godes 2008). Also potentially consistent with SET, Shiller (1990) provides survey evidence that people talked more about real estate in U.S. cities that have experienced rising real estate prices than those that have not. ${ }^{7}$

Our key assumption about the receivers of messages is that they are subject to the representativeness heuristic of (Tversky and Kahneman 1974). This implies that they overextrapolate past returns and are subject to selection neglect, meaning that they do not adjust adequately for the fact that they disproportionately receive messages from others about high rather than low experienced returns. Thus, message receivers do not account for the SET of message senders. Selection neglect is to be expected when individuals with limited processing power automatically process data in fast intuitive ways rather than taking the effortful cognitive step of adjusting for selection bias.

The representativeness heuristic is the key psychological principle underlying the model, but we also derive implications that rely upon the additional assumption that investors pay

\footnotetext{
${ }^{7}$ There is also extensive evidence of internal self-enhancing thought processes, such as the tendency of people to attribute successes to their own virtues, and failures to external circumstances or luck (Bem 1972; Langer and Roth 1975). Such processes encourage people to think more about their successes than their failures, as in the model of Bénabou and Tirole (2002). Such self-enhancing thinking is likely to result in self-enhancing bias in conversation. There has also been an experimental study of how agents report return information that is already known to recipients (Choi 2019).
} 
greater attention to more extreme returns. When cognitive processing power is limited, a focus on extremes is a useful heuristic, as extreme news tends to be highly informative. There is much evidence from the psychology of attention that extreme cues tend to be more salient than moderate cues, and therefore are more often noticed and encoded for later retrieval (Fiske 1980; Moskowitz 2004; Morewedge, Gilbert, and Wilson 2005). ${ }^{8}$

Many behavioral finance models of investor behavior assume overextrapolation of either fundamentals or returns, and there is also extensive evidence of such beliefs. ${ }^{9}$ There is also extensive empirical evidence that people do not adequately adjust for selection bias in the data they observe. ${ }^{10}$

\subsection{Sending and Receiving Functions}

To formally capture SET, we assume that an investor reports the performance of his/her investment strategy with a probability that increasing in investment returns. Specifically, we assume a sending function, $s$, that is increasing in returns, and for simplicity we assume it is linear:

$$
s(\tilde{R})=\beta \tilde{R}+\gamma, \quad \beta, \gamma>0
$$

where $\tilde{R}$ denotes investment returns.

The more tightly bound is the sender's self-esteem or reputation to return performance, the stronger is SET, and therefore the higher is $\beta$. The constant $\gamma$ reflects the conversability of the investment choice. When the investment is an attractive topic for conversation, the sender raises the topic more often. Empirically, an investor's self-enhancement parameter $\beta$ can be identified by psychometric testing, or based on other features of self-enhancing behavior.

In equation (1), the sending probability is a continuous and increasing function of returns, so that even low returns are sometimes reported and high returns are not always reported. This is consistent with the idea that people are more eager to report high

\footnotetext{
${ }^{8}$ Salience of extremes is consistent with evidence that individual investors are net buyers of stocks that experience extreme one-day returns of either sign (Barber and Odean 2008), and that extreme gains or losses at other time horizons are associated with higher probability of both selling and of buying additional shares of stocks that investors currently hold (Ben-David and Hirshleifer 2012). It is also reflected in the salience theory of choice under risk of Bordalo, Gennaioli, and Shleifer $(2012,2013)$.

${ }^{9}$ Theory: DeLong et al. (1990), Hong and Stein (1999), Barberis and Shleifer (2003), Barberis et al. (2015), Hirshleifer, Li and Yu (2015), and Barberis et al. (2018). Evidence: (Smith, Suchanek, and Williams 1988; Choi, Laibson, and Madrian 2010).

${ }^{10}$ Evidence of selection neglect is provided, e.g., by Nisbett and Ross (1980) and Brenner, Koehler, and Tversky (1996), and, in the financial context, Koehler and Mercer (2009).
} 
returns than low returns, but are constrained by conversational norms. Owing to norms against bragging, people do not always report high returns; and conversational norms for responsiveness sometimes push senders to reporting even low returns. Research on selfpresentation and impression management finds that people seek to report positively about themselves, as constrained by the need to be plausible and to satisfy norms for modesty (Goffman 1961; Schlenker 1980).

The selection neglect on the receiving investor's end of a message is modeled as a quadratic function of reported returns. Specifically, the probability that a receiving investor "listens" to the message received and adopts the investment strategy is $r(\tilde{R})$, where

$$
r(\tilde{R})=a \tilde{R}^{2}+b \tilde{R}+c, \quad a, b, c>0
$$

In the Internet Appendix, we show how the functional forms for $s$ and $r$ arise naturally under reasonable assumptions. We assume that the support of the return distribution is such that $s(\tilde{R}) \in[0,1]$ and $r(\tilde{R}) \in[0,1]$.

The positive parameter $b$ captures the greater persuasiveness of higher sender returns. So $b$ reflects the degree to which receivers naively extrapolate past strategy returns. One or a few recent observations of the performance of a trading strategy generally convey little information about its future prospects. But according to the representativeness heuristic, investors treat small samples as highly informative, consistent with $b>0$. Furthermore, other things equal we expect extreme returns to be more attention-grabbing, and therefore more persuasive. This is reflected in the convexity of the receiving schedule, i.e., $a>0$. The parameter $c$ captures a return-independent susceptibility of receivers to influence of the sender's report, reflecting a tendency to conform to or be swayed by the behavior of others. $^{11}$

\subsection{Social Interaction and Investment Strategies}

We consider a setting with a very large number, $N$, of investors. Time is discrete, $t=$ $0,1,2, \ldots$, where we think of one time period as being fairly short.

There are two mutually exclusive investment strategies available to each investor at each point in time, an active strategy $A$ that generates returns $\tilde{R}_{A}^{t}$, and a passive strategy $P$

\footnotetext{
${ }^{11}$ In our specification of the receiving function, conversion depends only on the sender's reported return. In reality, a receiver may compare this return with the receiver's own return. As a robustness check, we have verified that similar results apply when the receiver's switch decision depends on the difference in return between sender and receiver.
} 
that generates returns $\tilde{R}_{P}^{t}$. We will often suppress the $t$ superscript. Investors who choose the active and passive strategies are said to be of type $A$ and $P$, respectively. The returns of $\left(\tilde{R}_{A}^{t}\right.$ and $\left.\tilde{R}_{P}^{t}\right)$ are jointly i.i.d. across time periods.

The fraction of active investors among the population at time $t$ is $f_{t}$. Investors are finitely lived. They are randomly replaced with new investors at the rate of $\lambda$ per period. The fraction of new investors who initially choose an active strategy is exogenously determined by a constant $q \in[0,1]$.

The expectation, volatility, and skewness of the returns to the $A$ and $P$ investment strategies are $\mu_{i}, \sigma_{i}, \gamma_{i}$, where $i \in\{A, P\}$. Here, we assume that $\mu_{P}=\mu_{A}+D, D \geq 0$, $\sigma_{A}>\sigma_{P}$, and $\gamma_{P}=0$, whereas $\gamma_{A} \geq 0$, in line with the stylized facts documented in the literature about the returns on passive and active investments. For simplicity, we also normalize expected returns by assuming that $\mu_{P}=0$. We call $D$ the return penalty, rather than the "cost" of active trading, because a major part of the welfare loss may come from lack of diversification and excessive idiosyncratic risk-bearing. So even if it were the case that $D<0$, the $A$ 's could be worse off than $P^{\prime}$ 's. ${ }^{12}$

To summarize, active investing means choosing strategies with return distributions that have higher volatility and possibly also higher skewness. This corresponds fairly well with common parlance, but there are possible exceptions. For example, a long-short strategy that achieved low risk, or a dynamic hedging strategy that generated a riskfree payoff, would not be active in the sense we are using.

In each period, a (small) fraction $2 \kappa$ of investors are randomly selected as potential senders, and each such investor is matched with a randomly selected potential receiver among the remaining investors. Each potential sender of type $i \in\{A, P\}$, sends a message with probability $s\left(\tilde{R}_{i}\right)$, where conditional on sender returns, the outcome that a message is sent is i.i.d. across potential senders. This is a proxy for the intensity of social interaction. It could, for example, reflect how often people meet with each of their friends and how many friends they have, as examined more explicitly in the analysis of social networks in Subsection 3.4. Each potential receiver listens to the message, if received, with probability $r\left(\tilde{R}_{i}\right)$, where conditional upon the level of return conveyed, whether a receiver chooses to listen to a given message is i.i.d., across potential receivers. An investor who switches investment strategy between time $t$ and $t+1$ is called a time- $t$ switcher, or simply a switcher.

\footnotetext{
${ }^{12}$ Greater transaction costs of active trading (not modeled here) would also be reflected in $D$.
} 
The transformation probability that a potential sender of type $A$ with return $R_{A}$ converts a potential receiver of type $P$ that he or she is paired to is $T_{A}\left(R_{A}\right)=r\left(R_{A}\right) s\left(R_{A}\right)$, and the probability that a sender of type $P$ converts a receiver of type $A$ is $T_{P}\left(R_{P}\right)=$ $r\left(R_{P}\right) s\left(R_{P}\right)$. By assumption, $r^{\prime}, s^{\prime}>0$, so $T_{A}^{\prime}\left(R_{A}\right), T_{P}^{\prime}\left(R_{P}\right)>0$. We define the unconditional transformation probabilities

$$
\bar{T}_{i}=E\left[s\left(\tilde{R}_{i}\right) r\left(\tilde{R}_{i}\right)\right], \quad i \in\{A, P\}
$$

and also their difference $\bar{T}=\bar{T}_{A}-\bar{T}_{P}$.

Investors who are not selected as potential receivers do not change their investment strategies (although they may be replaced by new agents with opposite strategies). Similarly, a potential receiver who is matched with a potential sender of the same type will not switch. Only potential receivers who are matched with potential senders of the opposite type are therefore potential switchers. The fraction of such potential switchers in a given period is then $2 \kappa f_{t}\left(1-f_{t}\right)$.

The (expected) transformation rate from $P$ to $A$ at time $t$ is $E\left[f_{t+1}-f_{t}\right]$, which, given our previous assumptions, can be written

$$
E\left[f_{t+1}-f_{t}\right]=(1-\lambda) f_{t}\left(1-f_{t}\right) \kappa \bar{T}+\lambda\left(q-f_{t}\right)
$$

It follows immediately that the expected transformation rate is linearly increasing in $\bar{T}$, a fact that we will make heavy use of going forward.

The (steady-state) fraction of active investors is the $\bar{f}$ that satisfies $E\left[f_{t+1}-f_{t}\right]=0$, i.e.,

$$
0=(1-\lambda) \bar{f}(1-\bar{f}) \kappa \bar{T}+\lambda(q-\bar{f}) .
$$

It follows from (4) that when $\bar{T}>0$,

$$
\begin{aligned}
\bar{f} & =x+\sqrt{x^{2}+\frac{\hat{\lambda} q}{\kappa \bar{T}}}, \quad \text { where } \\
x & =\frac{1}{2}\left(1-\frac{\hat{\lambda}}{\kappa \bar{T}}\right), \quad \text { and } \quad \hat{\lambda}=\frac{\lambda}{1-\lambda},
\end{aligned}
$$

whereas $\bar{f}=q$ when $\bar{T}=0$. Also, it is straightforward to show that $\bar{f}$ is a strictly increasing function in $\bar{T}$ and $\kappa$.

When $\bar{f}>q$, we say that the active investment strategy dominates, relative to its frequency without investor communication. We will usually assume that $q=\frac{1}{2}$, in which 
case dominance is equivalent to $A$ being more prevalent than $P$. The previous results then imply that $A$ dominates/is more prevalent when $\bar{T}>0$.

\section{Results}

\subsection{Convex Fund Flows}

Our first result concerns the transformation rate from the passive to the active strategy, conditioned on realized returns. Equivalently, this can be interpreted as the net flow of capital into $A$.

\section{Proposition 1}

1. Conditional upon strategy return outcomes, the transformation rate from $P$ to $A$ is increasing and strictly convex in the realized active return, $R_{A}$.

2. The sensitivity of the transformation rate from $P$ to $A$ as a function of $R_{A}, \frac{\partial E\left[f_{t+1}-f_{t}\right]}{\partial R_{A}}$, and the convexity of this relationship, $\frac{\partial^{2} E\left[f_{t+1}-f_{t}\right]}{\partial^{2} R_{A}}$, are increasing with $S E T$ as reflected in $\beta$, conversability as reflected in $\gamma$, attention of receivers to extremes as reflected in $a$, and the extrapolativeness of receivers $b$.

3. The sensitivity of the expected transformation rate from $P$ to $A$ as a function $R_{A}$, $\frac{\partial E\left[f_{t+1}-f_{t}\right]}{\partial R_{A}}$, is increasing with the susceptibility of receivers $c$.

4. Each of the sensitivities and convex relationships in the first two parts are strengthened by increasing intensity of social interaction, $\kappa$. In other words, $\frac{\partial^{2} E\left[f_{t+1}-f_{t}\right]}{\partial R_{A} \partial \kappa}$, and $\frac{\partial^{3} E\left[f_{t+1}-f_{t}\right]}{\partial^{2} R_{A} \partial \kappa}>0$.

Part 1 of Proposition 1 provides our first main contribution, providing an explanation for the convexity of fund flows as a function of realized past returns, along with further implications for flow convexity. This intuition starts from the fact that higher realized active returns make active investors more eager to communicate their performance, and make passive investors more willing to listen and reevaluate their own strategy. These two effects are multiplicatively reinforcing, inducing convexity. (Convexity is further reinforced by the fact that receivers are especially attentive to extreme returns). Chevalier and Ellison (1997) and Sirri and Tufano (1998) find that investor funds flow into mutual funds with better performance (even though there is little evidence that performance is persistent). 
Furthermore, the flow-performance relationship is convex; flows are disproportionately into the best-performing funds. Lu and Tang (2015) find that 401(k) plan participants place a greater share of their retirement portfolios in risky investments (equity rather than fixed income) when their coworkers earned higher equity returns in the preceding period.

Furthermore, and consistent with Part 4, there is evidence that convexity of investment flows derive from social interaction. Kaustia and Knüpfer (2012) report a strong positive relation between new participation in the stock market in Finland and neighbors' recent stock returns in the range of positive returns. They find that the likelihood of entry does not decrease as returns fall below zero, consistent with people not talking about inferior outcomes. The greater strength of the effect in the positive range is consistent with the convexity prediction. ${ }^{13}$

Parts 2-3 include untested predictions that are distinctive to our model. For example, since past literature has provided empirical proxies for sociability, it will be valuable to test whether greater sociability is associated with greater slope and convexity of the transformation of investors to active investing as a function of past returns on $A$. It is also possible to test for the effects of variation in SET as reflected in $\beta$, using psychometric testing or by exploiting findings from cross-cultural psychology to test for differences in investment behaviors across countries or ethnic groups. For example, a nonsocial model with extrapolative beliefs would not share the predictions of Parts 2 and 3 of Proposition 1.

\subsection{Predominance of the Active Strategy}

We show in this subsection that higher variance and skewness promote the spread of investment strategies (the second and third main contributions of this paper), and that the active strategy can dominate even if it bears a positive return penalty (the fourth main contribution of the paper). These findings derive from reinforcing effects. Owing to SET, the spread of $A$ over $P$ is favored by increases in the volatility and skewness of $A$ relative to $P$. Furthermore, owing to greater attention to extremes $(a>0)$, the greater skewness of $A$ $\left(\gamma_{A} \geq \gamma_{P}\right)$ also promotes the spread of $A$. The effect is strong enough that $A$ can dominate even if it (in contrast with our model assumption) $A$ had lower expected returns $(D>0)$.

Proposition 2 In an economy with $\sigma_{A}>\sigma_{P}>0, \gamma_{A} \geq \gamma_{P}=0$, there exists a $\bar{D}>0$ such that for all $D<\bar{D}$, the active strategy dominates, $\bar{f}>\frac{1}{2}$.

\footnotetext{
${ }^{13}$ Our model does not imply a literally zero effect in the negative range, but a weaker effect within this range (as predicted by Proposition 1) would be statistically harder to detect.
} 
Furthermore, the volatility and skewness of $A$ promote its dominance :

Proposition 3 The steady state fraction of $A, \bar{f}$ :

1. Decreases with the return penalty to active trading, $D$;

2. Increases with active volatility, $\sigma_{A}$;

3. Increases with active skewness, $\gamma_{A}$.

Based upon a plausible additional assumption about pricing - that the higher the demand for a security, the higher its price and therefore the lower its expected long-run future return, we can interpret the comparative statics from Proposition 3 as comparative statics on the expected returns of active investors (also justified formally in the equilibrium model in Section D of the Appendix). Part 1 says that if the average return penalty $D$ to active trading is larger, $A$ will be less successful in spreading through the population.

Part 2 implies that there is greater investor demand for more volatile stocks (our second main contribution). Consistent with Part 2, Goetzmann and Kumar (2008) document that underdiversified investors prefer stocks that are more volatile. A further empirical implication of Part 2 is that in periods in which individual stocks have high idiosyncratic volatility, all else equal there will be greater holding of and volume of trade in individual stocks. Intuitively, during such periods A's have more extreme returns to report selectively.

This implication is in sharp contrast with the prediction of rational investing under portfolio theory, which suggests that in periods of high idiosyncratic volatility, the gains to holding a diversified portfolio rather than trading individual stocks is especially large. There are theories of bubbles in which high return volatility might be associated with high stock trading because investors are experiencing especially strong sentiment or misperceptions. A distinctive implication of the prediction here is that when an increase in the volatility of fundamentals is the driver of an increase in return volatility, there will still be an increase in stock holding and trading volume.

The greater demand of investors for a higher-volatility stock implies that it will have a higher price and lower expected return. This is consistent with the idiosyncratic volatility puzzle that stocks with high idiosyncratic risk earn low subsequent returns (Ang et al. (2006, 2009)). This apparent overpricing is stronger for firms held or traded more heavily by retail investors (Jiang, Xu, and Yao 2009; Han and Kumar 2013), for whom we would 
expect conversational biases to be strong. Thus, the theory offers a new social explanation for the idiosyncratic volatility puzzle: the high returns generated by volatile stocks are heavily discussed, which increases the demand for such stocks, driving up their prices.

A plausible nonsocial explanation for the idiosyncratic volatility puzzle is that realization utility or prospect theory with probability weighting creates a preference for volatile portfolios and stocks (Barberis and Huang 2008; Boyer, Mitton, and Vorkink 2010). A distinctive implication of our approach is that the effect derives from social interaction. Consistent with social interaction playing a role, in tests using extensive controls, there is evidence suggesting that the attraction to high volatility is greater among urban investors (Kumar (2009)).

High volatility in general derives from factor loadings as well as idiosyncratic volatility. So Part 2 also implies investors will tend to be attracted to high-beta stocks, pushing their price upward (and thereby depressing their expected returns). This is consistent with the anomaly that high beta stocks underperform and low beta stocks overperform (Baker, Bradley, and Wurgler 2011; Frazzini and Pedersen 2014).

Part 3 implies that conversation especially encourages demand for securities with high skewness (our third main contribution). Mitton and Vorkink (2007) and Goetzmann and Kumar (2008) document that underdiversified individual investors (presumably naive investors - whom we would expect to be most subject to social influence) tend to choose stocks with high skewness. Examples of skewed securities include options, and 'lottery stocks', such as real option firms that have a small chance of a jackpot outcome. As more investors adopt the strategy favoring purchase of positively skewed securities, the expected returns of such securities is depressed. This is consistent with the empirical finding that ex ante return skewness is a negative predictor of future stock returns (Conrad, Dittmar, and Ghysels 2013; Eraker and Ready 2015). ${ }^{14}$

This implication for the attraction of individual investors to lottery stocks is among this paper's key contributions. Existing explanations for this phenomenon have focused solely on an inherent individual characteristic - nontraditional preferences. In Brunnermeier and Parker (2005), agents who optimize over beliefs prefer skewed payoff distributions. In

\footnotetext{
${ }^{14}$ There is also evidence from initial public offerings (Green and Hwang 2012) and general samples (Bali, Cakici, and Whitelaw 2011) that lottery stocks are overpriced, and that being distressed (a characteristic that leads to a lottery payoff distribution) on average predicts negative abnormal returns (Campbell, Hilscher, and Szilagyi 2008). Boyer and Vorkink (2014) find that the ex ante skewness of equity options is a negative cross-sectional predictor of option abnormal returns.
} 
Barberis and Huang (2008), prospect theory with probability weighting creates a preference over portfolio skewness, which induces a demand for 'lottery' (high idiosyncratic skewness) stocks that contribute to portfolio skewness.

A key difference of our approach from the approaches of these papers is that investors are attracted to lottery stocks without any inherent preferences over beliefs or over portfolio skewness. Instead, biases in the transmission process cause the purchase of lottery stocks to be contagious. Indeed, in our approach, the attraction to variance and skewness derives from investor responses to past realizations, so investors need not even understand the statistical concepts of variance or skewness. The inherently social nature of our results offers a possible explanation for the empirical association of high social interaction with gambling and lottery behaviors. In our setting, greater social interaction increases contagion, thereby increasing the holdings of lottery stocks. ${ }^{15}$

\subsection{The Role of Communicability and Intensity of Social Inter- action}

Our model provides a natural link between the dominance of investment strategies and their communicability, which we define as the characteristics of the social transmission process that determine the probability that return messages about a strategy are conveyed to other investors and cause those investors to adopt it. The parameters $\{\beta, \gamma, a, b, c\}$ jointly capture communicability in our model. Furthermore, $\kappa$, the meeting rate, measures the intensity of social interaction. Earlier we derived results relating communicability to the rate at which investors convert from $P$ to $A$, conditional on strategy return outcomes, in Parts 2 and 3 of Proposition 1. Our next results show how communicability and intensity of social interaction increase the steady-state frequency of the active strategy. This provides our fifth main contribution.

Proposition 4 In an economy with $\sigma_{A}>\sigma_{P}>0, \gamma_{A} \geq \gamma_{P}=0$, there exists a $\bar{D}>0$ of the return penalty $D$ such that if $D<\bar{D}$, the steady state fraction, $\bar{f}$, of investors following the active strategy, increases with:

\section{SET, $\beta$;}

\footnotetext{
${ }^{15}$ We formalize this conclusion in Section 3.4, Proposition 6, where we show that the expected number of active investors - in this context, investors in lottery stocks - increases with the intensity of social interactions, $\kappa$.
} 


\section{The conversability, $\gamma$;}

3. Attention of receivers to extremes, a;

4. The extrapolativeness of receivers, $b$.

5. The intensity of social interaction, $\kappa$.

Proposition 4 describes how several characteristics of the social transmission process affect the evolutionary predominance of $A$. Part 1 states that greater SET as reflected in $\beta$ promotes evolution toward $A$, because SET causes greater reporting of the high returns that make $A$ enticing for receivers. Active investment $A$ more often generates extreme returns for SET to operate upon through higher factor loading, idiosyncratic volatility, or more positive idiosyncratic skewness. Empirically, $\beta$ as a reflection of the need for self-enhancement could be estimated using psychometric testing.

Part 2 states that greater conversability, as reflected in $\gamma$, can help $A$ spread because sending events tend to be more influential for an $A$ than a $P$ sender. The reason for this is that receivers pay greater attention to extreme returns $(a>0)$, which are more often generated by the $A$ strategy. Part 2 is consistent with active trading becoming more popular when people become more talkative about their investment performance. Examples include the rise of communication technologies, media, and such social phenomena as ubiquitous computing, stock market chat rooms, investment clubs, and blogging. This raises the possibility that the rise of these phenomena - to the extent that this occurred for reasons other than a rising stock market, such as technological change - contributed to the internet bubble. ${ }^{16}$ If greater general sociability is associated with greater comfort in discussing performance information, then in any given conversation it increases the unconditional probability that the sender will discuss returns; i.e., it increases $\gamma$. So if the expected return of $A$ is not too low, we have the empirical implication that greater sociability increases the equilibrium frequency of the active strategy.

\footnotetext{
${ }^{16}$ Another possible interpretation of the distinction between active versus passive strategies is that active strategies are more conversable (less conventional, more affect-triggering, or more arousing). This can be captured by replacing $\gamma$ in the sending function with $\gamma_{A}$ and $\gamma_{P}$, where $\gamma_{A}>\gamma_{P}$. However, our model generates a survival advantage for $A$ even without it having a conversability advantage. We have verified that $\gamma_{A}>\gamma_{P}$ favors the spread of $A$. Although fairly obvious, this point provides the additional empirical implication that there will be relative overvaluation of stocks whose 'glamour' characteristics make them attractive for conversation. Such glamour characteristics include growth, recent IPO, sports, entertainment, media, and innovative consumer products, so this implication is consistent with some known return anomalies.
} 
In Part 3, greater attention by receivers to extreme outcomes, as reflected in $a$ promotes the spread of $A$ over $P$. This is because $A$ generates more of the extreme returns which, when $a$ is high, are especially noticed and more likely to persuade receivers. This effect is reinforced by SET, which causes greater reporting of extreme high returns. This $a$ parameter can be estimated empirically; Barber and Odean (2008) estimate the effects of investor attention to extreme returns.

In Part 4, greater extrapolativeness of receivers, as reflected in $b$, helps $A$ spread by magnifying the effect of SET. This suggests that active investing will be more popular when extrapolative beliefs are stronger (past returns are perceived to be more informative about the future). Past empirical literature has estimated investor extrapolativeness of expectations using both survey approaches (Case and Shiller 1988; DeBondt 1993; VissingJorgensen 2003) and field evidence (Haruvy, Lahav, and Noussair 2007; Greenwood and Shleifer 2014; Hoffmann, Post, and Pennings 2015); such estimates provide a possible means of testing this prediction.

Part 5 highlights a distinctive feature of our theory, that the effects we identify derive from social interaction, and are therefore predicted to be stronger in times and places with greater intensity of social interactions, as reflected in $\kappa$. For example, population density is often used as an empirical proxy for social connectedness Empirically, participation in online communities (which are associated with social interaction) has been found to be associated with riskier financial decisions, with a stronger effect for more active participants (Zhu et al. (2012)). A similar intuition suggests that greater social connectedness (a larger number of links between individuals) will also strengthen the effects we derive. This point provides additional empirical predictions in relation to proxies for social connectedness at both the population level and, in the next Subsection 3.4, at the individual level.

Consistent with a role for social contagion in the attraction to lottery distributions, people who live in urban areas buy lottery tickets more frequently than individuals who live in rural areas (Kallick et al. (1979)). Furthermore, there is evidence suggesting that the preference for high skewness stocks is greater among urban investors, after controlling for demographic, geographic, and personal investing characteristics (Kumar 2009). ${ }^{17}$ In addition, as mentioned in the introduction, an empirical test of our model finds that lotterylike features (skewness and volatility) negatively predict returns more strongly when the

\footnotetext{
${ }^{17}$ Kumar (2009) empirically defines lottery stocks as stocks with high skewness, high volatility, and low price, so his findings do not distinguish the effects of skewness versus volatility.
} 
intensity of social interaction is higher, as proxied by either population density or the Social Connectedness Index from Facebook (Bali et al. (2019)).

\subsection{Investor Behavior in a Social Network}

Our model also provides strong novel empirical predictions about how social connections between investors influence investing behavior, providing the sixth and final main contribution of the paper. In reality, potential senders and receivers are not randomly matched in the whole population. Investors tend to communicate with the subset of others with whom they have social ties, such as friends, members of the same club or online community, and so forth. So the transmission of strategies between investors depends on their network positions.

We have extended the model to include a social network; the formal model is available in the online appendix. Since formal analysis of the social network framework requires a substantial amount of notation, and the results are very intuitive, we provide an informal presentation in the body of the paper.

In our extension, each investor, $n$, is connected to a set of other investors $\mathcal{D}_{n}$, which is a subset of the full set of $N$ agents. These represent the only investors an investor may receive messages from or send messages to. Specifically, in each period the fraction $2 \kappa$ of all the pairs of investors who are connected are matched, half as potential senders and the matched half as potential receivers. It follows that investors with many connections are more likely to be selected to become senders and receivers than are investors with few connections. Moreover, the probability that an investor changes type depends on the type and performance of the investor's connections, rather than of the general population. This intuition leads to Propositions 5 and 6, which extend our previous results to provide predictions about the behavior of specific investors based on their individual positions in the social network.

Proposition 5 In the model with a social network

1. For an investor $n$ with a given number of connections, the probability that investor $n$ switches strategy is increasing in the number of $n$ 's connections to investors of the opposite type, and in the performance of n's connections that are of the opposite type.

2. The probability that investor $n$ switches strategy is strictly convex in each of the returns of the opposite-type investors that $n$ is connected to. 
3. The probability that investor $n$ of a given type switches to the type of a neighbor is increasing in the skewnesses of the portfolio returns of each of n's network neighbors. If the return penalty to $A$ is sufficiently small, then the probability that investor $n$ of type $P$ converts is also increasing in the return volatilities of each of $n$ 's neighbors.

Proposition 5 provide several new predictions that are testable using data on investor social networks. Some of these predictions are untested, but there is supporting evidence for Part 1. Survey evidence indicates that greater household involvement in social activities is associated with greater stock market participation both in the U.S. (Hong, Kubik, and Stein 2004) and in ten European countries (Georgarakos and Pasini 2011). Furthermore, Heimer (2014) documents that social interaction is more prevalent amongst active investors who buy and/or sell stocks than passive investors who hold U.S. savings bonds, thereby supporting our explanation for the active investing puzzle in which informal communication tends to promote active rather than passive strategies.

Finally, we turn to implications about how individual social connectedness, and personal communicability characteristics of an investor and the investor's neighbor, affect an investor's attraction to the active strategy. We also extend the model to allow for individual differences in communicability, in addition to differences in network connectedness.

Proposition 6 In the model with a social network, there exists a $\bar{D}>0$ such that

1. If $D<\bar{D}$, the probability that a passive investor $n$ switches to $A$ in the next period increases with that investor's attention to extremes, $a_{n}$, and extrapolativeness, $b_{n}$.

2. If $D<\bar{D}$, the probability that a passive investor $n$ switches to $A$ in the next period increases with each of that investor's neighbors' SET, $\beta_{m}$, and conversability, $\gamma_{m}$, $m \in \mathcal{D}_{n}$.

As compared with investment professionals, individual investors are almost surely influenced more heavily by casual social communication of performance anecdotes relative to independent analysis and investigation. This suggests that the predictions of Propositions 5-6 that social interaction favors active investing will apply more strongly to individual investors than to professionals.

The implications of Proposition 6 are empirically testable. Part 1 states that investors with higher individual attention to extremes and/or extrapolativeness have higher probability of becoming $A$ 's. Part 2 indicates that the conversion probability of a $P$ switching 
to $A$ increases with the SET $\left(\beta_{m}\right)$ and conversability $\left(\gamma_{m}\right)$ of each of that investor's neighbors. (Here cross-investor differences in conversability reflect the fact that some people find investments to be a more attractive topic for conversation than do other people.)

The finding of Proposition 5 Part 1 that people tend to switch more when they are connected more to those of the opposite type suggests that in the economy as whole, if people have a propensity to socialize more with users of the same strategy, the rate of conversion will be lower. Such a tendency to preferentially socialize with those of similar type is called homophily. Homophily in our context reflects the fact that people like talking to each other about shared interests, which is likely to be just as true for investments as other activities. We analyze these issues in the online appendix, and find that the transformation rate and steady state fraction of $A$ 's is decreasing with homophily (the tendency for connections to be with others of the same type). Intuitively, greater homophily reduces the effective number of social interactions, since investors of opposite type are less likely to have communication and conversion. So the dominance of $A$ is reduced.

\section{Concluding Remarks}

We offer a new social approach to investment decision-making and asset prices, accounting for the imperfectly rational process by which ideas are transmitted between investors in their social network. We argue that success in the struggle for survival between investment strategies is determined by the sending function, which describes the probability that a sender communicates a strategy and its performance, and the receiving function, which describes the probability that this information converts the receiver to that strategy.

In the model, owing to self-enhancing transmission, senders' propensity to communicate their returns is increasing in sender return. The propensity of naive receivers to be converted is also increasing in sender return. Owing to the salience of extremes, the propensity of receivers to attend to and be converted by the sender is convex in sender return. These shapes of the sending and receiving functions, together with the intensity of social interactions describe the social transmission process. The psychological traits of investors determine the parameters of the sending and receiving functions.

We find that active strategies - those with high volatility, skewness, and personal engagement, spread after they experience high returns, and that this relationship is convex. As returns are realized, and as investors communicate with and persuade each other over 
time, the system evolves to a dynamically stable outcome with a high frequency of active investing. So in contrast with traditional behavioral finance models, active strategies tend to spread through the population even if investors have no inherent preference over their characteristics. The model therefore provides a new, social approach to understanding investor behavior. Also, since this attraction to variance and skewness derives from investor responses to past realizations, our model does not require that investors understand the statistical concepts of variance or skewness.

In particular, the evolutionary predominance of investors who adopt active strategies provides a social explanation for anomalies such as the lottery, volatility, beta, and IPO effects in capital market equilibrium. These effects depend on empirically observable parameters of the sending and receiving functions and the social network, leading to a rich set of additional empirical implications about investor trading and return anomalies.

More generally, we suggest that a fruitful direction for understanding how social interactions affect financial decisions is to study the factors that shape the sending and receiving functions, i.e., that cause an investor to talk about an investment idea, or to be receptive to such an idea upon hearing about it. Conversations are influenced by chance circumstances, subtle cues, and even trifling costs and benefits to the transactors. This suggests that variations in social environment that may seem trifling at the individual level can have important effects on economic outcomes. For example, the model suggests that a shift in the social acceptability of talking about one's successes, or of discussing personal investments more generally, can have large effects on risk taking and active investing. This suggests a possible explanation for both secular and higher-frequency shifts in investor behavior.

Much of the empirical literature on social interactions focuses on whether information or behaviors are transmitted, and on what affects the strength of social contagion. Our approach suggests that it is valuable to understand how biases in the transmission process affect decision making and economic outcomes.

It has often been argued that social interactions contribute to shifts in investor sentiment and bubbles (e.g., Shiller (2000)). Our model explains the dynamics of shifts in the popularity of different strategies as a function of past returns. As such, it offers a microfoundation for swings in investor sentiment.

To further explore sentiment and bubbles, our model could be extended to allow for overshooting and correction, by having the sending and the receiving functions depend on 
the sender's return over multiple periods (rather than just the most recent period return). Alternatively, if an increase in the fraction of investors who adopt an active strategy makes it more socially acceptable to discuss one's investment successes, the popularity of the active strategy will be self-reinforcing. So our model, and more generally the social finance approach, offers a possible framework for modeling how the spread of investment ideas causes overshooting, bubbles and crashes. 


\section{References}

Ammann, M. and N. Schaub (2016, June). Social interaction and investing: Evidence from an online social trading network. Working paper, University of St. Gallen.

Ang, A., R. J. Hodrick, Y. Xing, and X. Zhang (2006, February). The cross-section of volatility and expected returns. Journal of Finance 61(1), 259-299.

Ang, A., R. J. Hodrick, Y. Xing, and X. Zhang (2009, January). High idiosyncratic volatility and low returns: International and further U.S. evidence. Journal of Financial Economics 91(1), 1-23.

Baker, M., B. Bradley, and J. Wurgler (2011, January/February). Benchmarks as limits to arbitrage: Understanding the low-volatility anomaly. Financial Analysts Journal $67(1), 40-54$.

Bali, T. G., N. Cakici, and R. Whitelaw (2011, February). Maxing out: Stocks as lotteries and the cross-section of expected returns. Journal of Financial Economics 99(2), $427-446$.

Bali, T. G., D. A. Hirshleifer, L. Peng, and Y. Tang (2019, July). Attention, social interaction, and investor attraction to lottery stocks. Working paper, Georgetown University.

Barber, B., C. Heath, and T. Odean (2003, December). Good reasons sell: Reason-based choice among individual investors in the stock market. Management Science $49(12)$, 1636-1652.

Barber, B., Y.-T. Lee, Y.-J. Liu, and T. Odean (2009). Just how much do individual investors lose by trading? Review of Financial Studies 22(2), 609-632.

Barber, B. and T. Odean (2000a, April). Trading is hazardous to your wealth: The common stock investment performance of individual investors. Journal of Finance 55(2), $773-806$.

Barber, B. M. and T. Odean (2000b, January/February). Too many cooks spoil the profits: The performance of investment clubs. Financial Analyst Journal 56(1), 1725 .

Barber, B. M. and T. Odean (2002, March). Online investors: Do the slow die first? Review of Financial Studies 15(2), 455-488.

Barber, B. M. and T. Odean (2008, April). All that glitters: The effect of attention and news on the buying behavior of individual and institutional investors. Review of Financial Studies 21(2), 785-818.

Barberis, N., R. Greenwood, L. Jin, and A. Shleifer (2015, January). X-CAPM: An extrapolative capital asset pricing model. Journal of Financial Economics 115(1), $1-24$.

Barberis, N., R. Greenwood, L. Jin, and A. Shleifer (2018, August). Extrapolation and bubbles. Journal of Financial Economics 129(2), 203-227.

Barberis, N. and M. Huang (2008, December). Stocks as lotteries: The implications of probability weighting for security prices. American Economic Review 95(5), 20662100 . 
Barberis, N. and A. Shleifer (2003, May). Style investing. Journal of Financial Economics 68(2), 161-199.

Bem, D. J. (1972). Self-perception theory. Advances in Experimental Social Psychology 6, $1-62$.

Ben-David, I. and D. Hirshleifer (2012, August). Are investors really reluctant to realize their losses? Trading responses to past returns and the disposition effect. Review of Financial Studies 25(8), 2485-2532.

Bénabou, R. and J. Tirole (2002, August). Self-confidence and personal motivation. Quarterly Journal of Economics 117(3), 871-915.

Bisin, A. and T. Verdier (2000). Beyond the melting pot: Cultural transmission, marriage, and the evolution of ethnic and religious traits. Quarterly Journal of Economics $115(3)$, 955-988.

Bisin, A. and T. Verdier (2001, April). The economics of cultural transmission and the evolution of preferences. Journal of Economic Theory 97(2), 298-319.

Bordalo, P., N. Gennaioli, and A. Shleifer (2012, August). Salience theory of choice under risk. Quarterly Journal of Economics 127(3), 1243-1285.

Bordalo, P., N. Gennaioli, and A. Shleifer (2013, May). Salience and asset prices. American Economic Review 103(3), 623-628.

Boyer, B., T. Mitton, and K. Vorkink (2010, January). Expected idiosyncratic skewness. Review of Financial Studies 23(1), 169-202.

Boyer, B. H. and K. Vorkink (2014, August). Stock options as lotteries. Journal of Finance 59(4), 1485-1527.

Brenner, L. A., D. J. Koehler, and A. Tversky (1996, March). On the evaluation of one-sided evidence. Journal of Behavioral Decision Making 9(1), 59-70.

Brown, J. R., Z. Ivković, P. A. Smith, and S. Weisbenner (2008, June). Neighbors matter: Causal community effects and stock market participation. Journal of Finance 63(3), 1509-1531.

Brunnermeier, M. K. and J. Parker (2005, September). Optimal expectations. American Economic Review 95(4), 1092-1118.

Burnside, C., M. Eichenbaum, and S. T. Rebelo (2016, August). Understanding booms and busts in housing markets. Journal of Political Economy 124(4), 10881147.

Calvet, L. E., J. Y. Campbell, and P. Sodini (2007, October). Down or out: Assessing the welfare costs of household investment mistakes. Journal of Political Economy 115(5), 707-747.

Calvet, L. E., J. Y. Campbell, and P. Sodini (2009, February). Fight or flight? portfolio rebalancing by individual investors. Quarterly Journal of Economics 124(1), 301-348.

Campbell, J. Y., J. D. Hilscher, and J. Szilagyi (2008, December). In search of distress risk. Journal of Finance 63(6), 2899-2939.

Carhart, M. M. (1997, March). On persistence in mutual fund performance. Journal of Finance 52(1), 57-82.

Case, K. E. and R. J. Shiller (1988, November/December). The behavior of home buyers in boom and post-boom markets. New England Economic Review 80(3), 29-46. 
Chevalier, J. and G. Ellison (1997, December). Risk taking by mutual funds as a response to incentives. Journal of Political Economy 105(6), 1167-1200.

Choi, J. J., D. Laibson, and B. C. Madrian (2010, April). Why does the law of one price fail? An experiment on index mutual funds. Review of Financial Studies 23(4), 1405-1432.

Choi, J. J., D. Laibson, and A. Metrick (2002, June). How does the internet affect trading? Evidence from investor behavior in 401(k) plans. Journal of Financial Economics $64(3), 397-421$.

Choi, Y. (2019). When losers talk: Conversations, social norms, and information diffusion. Working paper.

Cipriani, M. and A. Guarino (2002). Social learning and financial crises. In Risk measurement and systemic risk: Proceedings of the third joint Central Bank research conference, pp. 77-83. Basel, Switzerland: The Committee on the Global Financial System, Bank for International Settlements Press.

Cipriani, M. and A. Guarino (2008, April). Herd behavior and contagion in financial markets. B.E. Journal of Theoretical Economics 8(1), Article 24.

Cohen, L., A. Frazzini, and C. J. Malloy (2008, October). The small world of investing: Board connections and mutual fund returns. Journal of Political Economy 116(5), 951-979.

Cohen, L., A. Frazzini, and C. J. Malloy (2010, August). Sell-side school ties. Journal of Finance 65(4), 1409-1437.

Conrad, J., R. F. Dittmar, and E. Ghysels (2013, February). Ex ante skewness and expected stock returns. Journal of Finance 68(1), 85-124.

Daniel, K. D., M. Grinblatt, S. Titman, and R. Wermers (1997, July). Measuring mutual fund performance with characteristic-based benchmarks. Journal of Finance 52(3), $1035-1058$.

DeBondt, W. F. M. (1993, November). Betting on trends: Intuitive forecasts of financial risk and return. International Journal of Forecasting 9(3), 355-371.

DeBondt, W. F. M. and R. H. Thaler (1995). Financial decision-making in markets and firms: A behavioral perspective. In R. A. Jarrow, V. Maksimovic, and W. T. Ziemba (Eds.), Finance, Handbooks in Operations Research and Management Science, Volume 9, Chapter 13, pp. 385-410. Amsterdam: North Holland.

DeLong, J. B., A. Shleifer, L. Summers, and R. J. Waldmann (1990). Positive feedback investment strategies and destabilizing rational speculation. Journal of Finance $45(2)$, 375-395.

DeMarzo, P., D. Vayanos, and J. Zwiebel (2001). Social networks and financial markets. Working paper, MIT and Stanford University.

DeMarzo, P., D. Vayanos, and J. Zwiebel (2003). Persuasion bias, social influence, and uni-dimensional opinions. Quarterly Journal of Economics 118, 909-968.

Duflo, E. and E. Saez (2002, July). Participation and investment decisions in a retirement plan: The influence of colleagues' choices. Journal of Public Economics 85(1), 121148. 
Duflo, E. and E. Saez (2003, August). The role of information and social interactions in retirement plan decisions: Evidence from a randomized experiment. Quarterly Journal of Economics 118(3), 815-842.

East, R., K. Hammond, and M. Wright (2007, June). The relative incidence of positive and negative word of mouth: A multi-category study. International Journal of Research in Marketing 24(2), 175-184.

Eraker, B. and M. J. Ready (2015, March). Do investors overpay for stocks with lotterylike payoffs? An examination of the returns on OTC stocks. Journal of Financial Economics 115(3), 486-504.

Escobar, L. and A. Pedraza (2019). Active trading and (poor) performance. Working paper, World Bank.

Fiske, S. T. (1980, June). Attention and weight in person perception: The impact of negative and extreme behavior. Journal of Personality and Social Psychology 38(6), 889-906.

Frazzini, A. and L. H. Pedersen (2014, January). Betting against beta. Journal of Financial Economics 111(1), 1-25.

French, K. R. (2008, August). Presidential address: The cost of active investing. Journal of Finance 63(4), 1537-1573.

Georgarakos, D. and G. Pasini (2011, October). Trust, sociability, and stock market participation. Review of Finance 15(4), 693-725.

Goetzmann, W. N. and A. Kumar (2008). Equity portfolio diversification. Review of Finance 12(3), 433-463.

Goffman, E. (1961). Encounters. Indianapolis, IN: Bobbs-Merrill.

Gray, W. R., S. Crawford, and A. E. Kern (2012, May). Do hedge fund managers identify and share profitable ideas? Working paper, Drexel University.

Green, T. C. and B.-H. Hwang (2012, February). Initial public offerings as lotteries: Skewness preference and first-day returns. Management Science 58(2), 432-444.

Greenwood, R. and A. Shleifer (2014, March). Expectations of returns and expected returns. Review of Financial Studies 27(3), 714-746.

Griffin, J. M., F. Nardari, and R. M. Stulz (2007, May). Do investors trade more when stocks have performed well? Evidence from 46 countries. Review of Financial Studies $20(3)$, 905-951.

Han, B. and A. Kumar (2013, April). Speculative retail trading and asset prices. Journal of Quantative and Financial Analysis 48(2), 377-404.

Han, B. and L. Yang (2013, June). Social networks, information acquisition, and asset prices. Management Science 59(6), 1444-1457.

Haruvy, E., Y. Lahav, and C. N. Noussair (2007, December). Traders' expectations in asset markets: Experimental evidence. American Economic Review 97(5), 19011920 .

Heimer, R. and D. Simon (2015, October). Facebook finance: How social interaction propagates active investing. Working paper, Brandeis University. 
Heimer, R. Z. (2014, November). Friends do let friends buy stocks actively. Journal of Economic Behavior 85 Organization 107(B), 527-540.

Hirshleifer, D., J. Li, and J. Yu (2015). Asset pricing with extrapolative expectations and production. Journal of Monetary Economics 76, 87-106.

Hoffmann, A. O., T. Post, and J. M. Pennings (2015, March). How investor perceptions drive actual trading and risk-taking behavior. Journal of Behavioral Finance 16(1), 94-103.

Hong, H., J. Kubik, and J. C. Stein (2005, December). Thy neighbor's portfolio: Wordof-mouth effects in the holdings and trades of money managers. Journal of $\mathrm{Fi}$ nance $60(6), 2801-2824$.

Hong, H. and J. C. Stein (1999, December). A unified theory of underreaction, momentum trading and overreaction in asset markets. Journal of Finance 54 (6), 2143-2184.

Hong, H. G., J. D. Kubik, and J. C. Stein (2004, February). Social interaction and stock market participation. Journal of Finance 59(1), 137-163.

Huang, J., K. D. Wei, and H. Yan (2007, May). Participation costs and the sensitivity of fund flows to past performance. Journal of Finance 62 (3), 1273-1311.

Huang, S., B.-H. Hwang, and D. Lou (2018, July). The speed of communication. Working paper, University of Hong Kong.

Ivković, Z. and S. Weisbenner (2007, July). Information diffusion effects in individual investors' common stock purchases: Covet thy neighbors' investment choices. Review of Financial Studies 20(4), 1327-1357.

Jiang, G. J., D. Xu, and T. Yao (2009). The information content of idiosyncratic volatility. Journal of Financial and Quantitative Analysis 44(1), 1 - 28.

Kallick, M., D. Smits, T. Dielman, and J. Hybels (1979). A survey of American gambling attitudes and behavior. Research Report Series, Survey Research Center, Institute for Social Research, University of Michigan.

Karlsson, N., G. F. Loewenstein, and D. J. Seppi (2009, February). The 'Ostrich Effect': Selective attention to information. Journal of Risk and Uncertainty 38(2), 95-115.

Kaustia, M. and S. Knüpfer (2012, May). Peer performance and stock market entry. Journal of Financial Economics 104(2), 321-338.

Kelly, M. and C. O. O'Grada (2000). Market contagion: Evidence from the panics of 1854 and 1857. American Economic Review 90(5), 1110-1124.

Koehler, J. J. and M. Mercer (2009, July). Selection neglect in mutual fund advertisements. Management Science 55(7), 1107-1121.

Kumar, A. (2009, April). Who gambles in the stock market? Journal of Finance 64 (4), 1889-1933.

Langer, E. J. and J. Roth (1975, December). Heads I win, tails it's chance: The illusion of control as a function of the sequence of outcomes in a purely chance task. Journal of Personality and Social Psychology 32(6), 951-955.

Leary, M. R. and R. M. Kowalski (1990, January). Impression management: A literature review and two-component model. Psychological Bulletin 107(1), 34-47. 
Lim, S. S., J. Ng, and B. Uzzi (2020, January). Biased information transmission in investor social network: Evidence from professional traders. Working paper, DePaul University.

Lu, T. and N. Tang (2015, May). Social interaction effects and individual portfolio choice: Evidence from 401(k) pension plan investors. Working paper, Peking University HSBC Business School.

Massa, M. and A. Simonov (2005, February). History versus geography: The role of college interaction in portfolio choice. Working paper, INSEAD.

Massa, M. and A. Simonov (2006, Summer). Hedging, familiarity and portfolio choice. Review of Financial Studies 19(2), 633-685.

Mitton, T. and K. Vorkink (2007). Equilibrium underdiversification and the preference for skewness. Review of Financial Studies 20(4), 1255-1288.

Mitton, T., K. Vorkink, and I. Wright (2018, July). Neighborhood effects on speculative behavior. Journal of Economic Behavior $\&$ Organization 151, 42-61.

Morewedge, C. K., D. T. Gilbert, and T. D. Wilson (2005, August). The least likely of times: How remembering the past biases forecasts of the future. Psychological Science 16(8), 626-630.

Moskowitz, G. B. (2004). Social Cognition: Understanding Self and Others. New York, NY: The Guilford Press.

Nisbett, R. and L. Ross (1980). Human Inference: Strategies and Shortcomings of Social Judgment. Englewood Cliffs, NJ: Prentice-Hall.

Özsöylev, H. N. and J. Walden (2011, November). Asset pricing in large information networks. Journal of Economic Theory 146(6), 2252-2280.

Peng, L. and W. Xiong (2006). Investor attention, overconfidence and category learning. Journal of Financial Economics 80(3), 563-602.

Schlenker, B. R. (1980). Impression Management: The Self-Concept, Social Identity, and Interpersonal Relations. Monterey, CA: Brooks/Cole Publishing Company.

Shiller, R. J. (1989). Market Volatility. Cambridge: MIT Press.

Shiller, R. J. (1990, Spring). Speculative prices and popular models. Journal of Economic Perspectives 4(2), 55-65.

Shiller, R. J. (2000). Irrational exuberance. Princeton, N.J.: Princeton University Press.

Shiller, R. J. (2017, April). Narrative economics. American Economic Review 107(4), 967-1004.

Shiller, R. J. and J. Pound (1989, August). Survey evidence on the diffusion of interest and information among investors. Journal of Economic Behavior and Organization 12(1), 47-66.

Shive, S. (2010, February). An epidemic model of investor behavior. Journal of Financial and Quantitative Analysis 45(1), 169-198.

Sicherman, N., G. Loewenstein, D. J. Seppi, and S. P. Utkus (2012, July). To look or not to look: Financial attention and online account logins. Working paper, Columbia University. 
Sims, C. (2003, March). Implications of rational inattention. Journal of Monetary Economics 50, 665-690.

Sirri, E. R. and P. Tufano (1998, October). Costly search and mutual fund flows. Journal of Finance 53(5), 1589-1622.

Smith, V. L., G. L. Suchanek, and A. W. Williams (1988, September). Bubbles, crashes and endogenous expectations in experimental spot asset markets. Econometrica 56(5), 1119-1151.

Statman, M., S. Thorley, and K. Vorkink (2006). Investor overconfidence and trading volume. Review of Financial Studies 19(4), 1531-1565.

Tversky, A. and D. Kahneman (1974, September). Judgment under uncertainty: Heuristics and biases. Science 185(4157), 1124-1131.

Vissing-Jorgensen, A. (2003). Perspectives on behavioral finance: Does "irrationality" disappear with wealth? Evidence from expectations and actions. NBER Macroeconomics Annual 2003 18, 139-194.

Welch, I. (1992, June). Sequential sales, leaning, and cascades. Journal of Finance $4^{7}(2)$, $695-732$.

Wojnicki, A. C. and D. Godes (2008, April). Word-of-mouth as self-enhancement. Working paper, University of Toronto.

Zhu, R. J., U. M. Dholakia, X. J. Chen, and R. Algesheimer (2012, June). Does online community participation foster risky financial behavior? Journal of Marketing Research 49(3), 394-407. 


\section{For Online Publication}

\section{A Proofs}

\section{A.1 Proof of Proposition 1:}

Define $\Delta f=f_{t+1}-f_{t}$. Note that

$$
\Delta f=f_{t}\left(1-f_{t}\right) \kappa\left(T_{A}\left(R_{A}\right)-T_{P}\left(R_{P}\right)\right)+\hat{\lambda}\left(q-f_{t}\right),
$$

where $T_{A}\left(R_{A}\right)=r\left(R_{A}\right) s\left(R_{A}\right)$, and $T_{P}\left(R_{P}\right)=r\left(R_{P}\right) s\left(R_{P}\right)$. At date $t, f_{t}$ is given.

Differentiating with respect to $R_{A}$ twice, and using the earlier conditions that $r^{\prime}\left(R_{A}\right), s^{\prime}\left(R_{A}\right)>$ 0 , that $s^{\prime \prime}\left(R_{A}\right)=0$ by $(1)$, and that $r^{\prime \prime}\left(R_{A}\right)>0$ by $(2)$, gives

$$
\begin{gathered}
\frac{\partial T_{A}\left(R_{A}\right)}{\partial R_{A}}=r^{\prime}\left(R_{A}\right) s\left(R_{A}\right)+r\left(R_{A}\right) s^{\prime}\left(R_{A}\right)>0 \\
\frac{\partial^{2} T_{A}\left(R_{A}\right)}{\partial\left(R_{A}\right)^{2}}=r^{\prime \prime}\left(R_{A}\right) s\left(R_{A}\right)+2 r^{\prime}\left(R_{A}\right) s^{\prime}\left(R_{A}\right)>0 .
\end{gathered}
$$

Since $R_{A}$ affects $T_{A}$ but not $T_{P}$, these formulas describe how active return affects both the expected net shift in the fraction of $A$ 's, and the expected unidirectional rate of conversion from $P$ to $A$.

Furthermore, substituting for the sending function $s\left(R_{A}\right)$ from (1) and the receiving function $r\left(R_{A}\right)$ from (2) into (A.2) and (A.3) gives

$$
\begin{aligned}
\frac{\partial T_{A}\left(R_{A}\right)}{\partial R_{A}} & =\left(2 a R_{A}+b\right)\left(\beta R_{A}+\gamma\right)+\beta\left(a R_{A}^{2}+b R_{A}+c\right) \\
\frac{\partial^{2} T_{A}\left(R_{A}\right)}{\partial\left(R_{A}\right)^{2}} & =2 a\left(\beta R_{A}+\gamma\right)+2 \beta\left(2 a R_{A}+b\right) .
\end{aligned}
$$

The fact that sending and receiving functions and their first and second derivatives are all positive signs some of the terms in parentheses. So it follows immediately from (A.4) that the sensitivity of the transformation rate of investors to $A$ as a function of past active return is increasing with the parameters of the sending and receiving functions, $\beta, \gamma, a, b$, and $c$. By (A.5), a similar point follows immediately for convexity as well, with the exception that $c$ does not enter into convexity. Furthermore, since $\kappa$ is multiplied by $T_{A}\left(R_{A}\right)-T_{P}\left(R_{P}\right)$ in equation (A.1), it also follows immediately that these effects are increasing with the intensity of social interactions, $\kappa$.

\section{A.2 Proof of Proposition 2}

From the discussion in the main text, it follows that we need to show that $\bar{T}=\bar{T}_{A}-\bar{T}_{P}>0$ under the assumption of the proposition.

Using the definitions of the sending and receiving functions, direct calculation yields

$$
\begin{aligned}
\bar{T}= & \bar{T}^{A}-\bar{T}^{P} \\
= & a \beta\left[\gamma_{A} \sigma_{A}^{3}-\gamma_{P} \sigma_{P}^{3}+3 \mu_{A}\left(\sigma_{A}^{2}-\sigma_{P}^{2}\right)\right]+B\left(\sigma_{A}^{2}-\sigma_{P}^{2}\right)-a \beta D^{3} \\
& -3 a \beta \mu_{A} D^{2}-\left[3 a \beta \mu_{A}^{2}+3(a \beta+B) \sigma_{P}^{2}+C\right] D
\end{aligned}
$$


where

$$
B=a \gamma+b \beta,
$$

and

$$
C=b \gamma+c \beta .
$$

It is easy to verify that $\bar{T}>0$ when $D=0$ and $\frac{\partial \bar{T}}{\partial D}<0$ when $D>0$ (see the proof of Proposition 3 , Part 1), so that $\bar{T}$ is decreasing with $D$ when $D>0$. On the other hand, when $D$ is very large (relative to a fixed set of other model parameters), $\bar{T}$ would be negative. Therefore, there exists a positive $\bar{D}$ corresponding to which $\bar{T}$ is zero. Then for all $D<\bar{D}, \bar{T}>0$, so the active strategy dominates.

\section{A.3 Proof of Proposition 3}

To show Part 1, we differentiate (A.6) with respect to $D$ to obtain that

$$
\frac{\partial \bar{T}}{\partial D}=-3 a \beta D^{2}-6 a \beta \mu_{A} D-\left[3 a \beta \mu_{A}^{2}+3(a \beta+B) \sigma_{P}^{2}+C\right]<0 .
$$

For Part 2, differentiating with respect to active volatility $\sigma_{A}$ gives

$$
\frac{\partial \bar{T}}{\partial \sigma_{A}}=3 a \beta \gamma_{A} \sigma_{A}^{2}+6 a \beta \mu_{A} \sigma_{A}+2 B \sigma_{A}>0
$$

Thus, the growth of $A$ increases with active volatility $\sigma_{A}$. Greater return variance increases the effect of SET on the part of the sender. Although high salience to receivers of extreme returns $(a>0)$ is not required for the result, it reinforces this effect. Indeed, even if there were no SET $(\beta=0)$, since $a>0$ implies that $B>0$, the result would still hold. Intuitively, high volatility generates the extreme outcomes which receive high attention.

For Part 3, differentiating with respect to skewness $\gamma_{A}$ of $A$ gives

$$
\frac{\partial \bar{T}}{\partial \gamma_{A}}=a \beta \sigma_{A}^{3}>0
$$

Thus, the advantage of $A$ over $P$ is increasing with return skewness of $A$.

\section{A.4 Proof of Proposition 4}

For Part 1, we differentiate with respect to $\beta$, the strength of SET. This reflects how tight the link is between the sender's self-esteem and performance.

$$
\begin{aligned}
\frac{\partial \bar{T}}{\partial \beta}= & a\left[\gamma_{A} \sigma_{A}^{3}-\gamma_{P} \sigma_{P}^{3}+3 \mu_{A}\left(\sigma_{A}^{2}-\sigma_{P}^{2}\right)\right]+b\left(\sigma_{A}^{2}-\sigma_{P}^{2}\right)-a D^{3} \\
& -3 a \mu_{A} D^{2}-\left[3 a \mu_{A}^{2}+3(a+b) \sigma_{P}^{2}+c\right] D \\
> & 0
\end{aligned}
$$


if $D \approx 0$ is sufficiently small. So greater SET increases the evolution toward $A$, because SET causes greater reporting of the high returns that make $A$ enticing for receivers. $A$ generates extreme returns for SET to operate upon through higher volatility, or more positive skewness.

For Part 2, differentiating with respect to conversability $\gamma$ gives

$$
\begin{aligned}
\frac{\partial \bar{T}}{\partial \gamma} & =a\left(\sigma_{A}^{2}-\sigma_{P}^{2}\right)-\left(b+3 a \sigma_{P}^{2}\right) D \\
& >0
\end{aligned}
$$

if $D$ is sufficiently small. Greater conversability $\gamma$ can help the active strategy spread because of the greater attention paid by receivers to extreme returns $(a>0)$, which are more often generated by the $A$ strategy. (If $D<0$, this effect is reinforced by the higher mean return of $A$. In this case an unconditional increase in the propensity to report returns tends to promote the spread of the sender's type more when the sender is $A$.) If $A$ earns lower return than $P$ on average, greater conversability incrementally produces more reporting of lower returns when the sender is $A$ than $P$, which opposes the spread of $A$.

For Part 3, recall that the quadratic term of the receiving function $a$ reflects greater attention on the part of the receiver to extreme profit outcomes communicated by the sender. Differentiating with respect to $a$ gives

$$
\begin{aligned}
\frac{\partial \bar{T}}{\partial a}= & \beta\left[\gamma_{A} \sigma_{A}^{3}-\gamma_{P} \sigma_{P}^{3}+3 \mu_{A}\left(\sigma_{A}^{2}-\sigma_{P}^{2}\right)\right]+\gamma\left(\sigma_{A}^{2}-\sigma_{P}^{2}\right)-\beta D^{3} \\
& -3 \beta \mu_{A} D^{2}-\left[3 \beta \mu_{A}^{2}+3(\beta+\gamma) \sigma_{P}^{2}\right] D \\
> & 0
\end{aligned}
$$

if $D$ is sufficiently small. So greater attention by receivers to extreme outcomes, $a$, promotes the spread of $A$ over $P$ because $A$ generates more of the extreme returns which, when $a$ is high, are especially noticed and more likely to persuade receivers. This effect is reinforced by SET, which causes greater reporting of extreme high returns.

For Part 4, differentiating with respect to how prone receivers are to extrapolating returns, $b$, gives

$$
\begin{aligned}
\frac{\partial \bar{T}}{\partial b} & =\beta\left(\sigma_{A}^{2}-\sigma_{P}^{2}\right)-\left(3 \beta \sigma_{P}^{2}+\gamma\right) D \\
& >0
\end{aligned}
$$

if $D$ is sufficiently small. Greater extrapolativeness of receivers helps $A$ spread by magnifying the effect of SET (reflected in $\beta$ ), which spreads $A$ because of the higher volatility of $A$ returns.

Finally, for $\kappa$, the result follows from the symmetric functional dependence of $\bar{f}$ on $\bar{T}$ and $\kappa$, $\bar{f}=\bar{f}(\kappa \bar{T})$, which implies that $\bar{f}$ is increasing in $\kappa$, just like it is increasing in $\bar{T}$.

\section{A.5 Proof of Proposition 5}

In this and the next Proof, we assume the presence of a social network, as follows: Investors are connected in an undirected social network represented by the graph $\mathcal{G}=(\mathcal{N}, \mathcal{E})$, where $\mathcal{N}$ is the set of investors and $\mathcal{E}$ is the set of edges connecting them. The set of investors $\mathcal{N}=\{1, \ldots, N\}$, 
and $(m, n) \in \mathcal{E} \subset \mathcal{N} \times \mathcal{N}$ if investors $m$ and $n$ are connected through a social tie. By convention, the network is undirected, i.e., $(m, n) \in \mathcal{E} \Leftrightarrow(n, m) \in \mathcal{E}$, and investors are not connected to themselves $((n, n) \notin \mathcal{N})$.

In the model, social ties could represent friendship, professional collaboration, membership in the same country club, or involvement with the same online community. If $(m, n) \in \mathcal{E}$, there is a chance that investor $m$ tells $n$ his investment strategy and performance. The set of investors that $n$ is socially linked to is $\mathcal{D}_{n}=\{m:(n, m) \in \mathcal{E}\} \subset \mathcal{N} \backslash\{n\}$, and $n$ 's degree (number of connections) is $d_{n}=\left|\mathcal{D}_{n}\right|$. An investor with a higher degree is said to be more connected. The total number of connections is $Q=\frac{1}{2} \sum_{n} d_{n}$.

Consider investor $n$, who has adopted a passive investment strategy. Given return realizations, $R_{A}$ and $R_{P}$, the transition probability for a sender from $A$ to $P$ is $T_{A}\left(R_{A}\right)$. Denote the subset of neighbors of investor $n$ that are type $A$ (resp. $P$ ) by $\mathcal{D}_{n}^{A}\left(\right.$ resp. $\left.\mathcal{D}_{n}^{P}\right)$.

We prove the result for a more general case than our base model in which, even within the same class of investment strategies $(A$ or $P$ ), investors may have different returns. Specifically, the return of an $A$ investor $m \in D_{n}^{A}$ is assumed to be $R_{A m}$. The main body considers the special case in which $R_{A m} \equiv R_{A}$ (is the same) for all active investors. In a period, the number $2 \kappa N$ links are chosen randomly in $\mathcal{E}$, with equal probability, and such that $(m, n)$ and $(n, m)$ are not both chosen, and we assume that $2 \kappa N<<Q$. Here, $n$ is the potential sender and $m$ the potential receiver in the chosen link $(n, m)$.

For a type $P$ investor $n$ to convert to $A$, he/she must (i) be selected for communication, which occurs with probability $2 \kappa d_{n} / Q$, (ii) be selected to be receiver, which occurs with probability $1 / 2$, (iii) communicate with an $A, m \in \mathcal{D}_{n}^{A}$, and finally (iv) be converted, which occurs with probability $T_{A}\left(R_{A m}\right)$. So the probability $\mathcal{C}$ that investor $n$ switches from $P$ to $A$ is therefore

$$
\mathcal{C}=\kappa \times \frac{\left|\mathcal{D}_{n}\right|}{Q} \times \frac{\left|\mathcal{D}_{n}^{A}\right|}{\left|\mathcal{D}_{n}\right|} \sum_{m \in \mathcal{D}_{n}^{A}} T_{A}\left(R_{A m}\right) .
$$

Clearly, this probability is increasing in the number of $A$ connections, $\left|\mathcal{D}_{n}^{A}\right|$. It is also increasing and strictly convex in the performance of each of these connections, since $T_{A}$ is and increasing strictly convex function of $R_{A m}$. Finally, an identical argument as in the proof of Proposition 3 applied to (A.13) implies that the probability is increasing in $\sigma_{A_{m}}$.

\section{A.6 Proof of Proposition 6}

An identical argument as in the proof of Proposition 1 applied to (A.13) implies that the probability is increasing in $a_{n}, b_{n}, \beta_{m}$, and $\gamma_{m}, m \in \mathcal{D}_{n}$.

\section{B Endogenizing the Receiving and Sending Functions}

We model here the determinants of the sending and receiving functions, and derive their functional forms. 


\section{B.1 The Sending Function}

To derive a sending function that reflects the desire to self-enhance, we assume that the utility derived from sending is increasing with own-return. Conversation is an occasion for an investor to try to raise the topic of return performance if it is good, or to avoid the topic if it is bad. Suppressing $i$ subscripts, let $\pi(R, x)$ be the utility to the sender of discussing his return $R$,

$$
\pi(R, x)=R+\frac{x}{\beta^{\prime}},
$$

where $\beta^{\prime}$ is a positive constant that measures the relative weight in the individual's utility on conversational context versus the desire to communicate higher returns. The more tightly the investor's self-esteem is tied to return performance, the higher is $\beta^{\prime}$. The random variable $x$ measures whether, in the particular social and conversational context, raising the topic of ownperformance is appropriate or even obligatory.

The sender sends if and only if $\pi>0$, so

$$
\begin{aligned}
s(R) & =\operatorname{Pr}\left(x>-\beta^{\prime} R \mid R\right) \\
& =1-F\left(-\beta^{\prime} R\right),
\end{aligned}
$$

where $F$ is the distribution function of $x$. If $x \sim U\left[\tau_{1}, \tau_{2}\right]$, where $\tau_{1}<0, \tau_{2}>0$, then

$$
\begin{aligned}
s(R) & =\frac{\tau_{2}+\beta^{\prime} R}{\tau_{2}-\tau_{1}} \\
& =\frac{\tau_{2}}{\tau_{2}-\tau_{1}}+\beta R,
\end{aligned}
$$

where $\beta \equiv \beta^{\prime} /\left(\tau_{2}-\tau_{1}\right)$, and where we restrict the domain of $R$ to satisfy $-\tau_{2} / \beta^{\prime}<R<-\tau_{1} / \beta^{\prime}$ to ensure that the sending probability lies between 0 and 1 . This will hold almost surely if $\left|\tau_{1}\right|,\left|\tau_{2}\right|$ are sufficiently large. Equation (B.3) is identical to the sending function (1) in Subsection 2.2 with

$$
\gamma \equiv \frac{\tau_{2}}{\tau_{2}-\tau_{1}}
$$

In the sender's utility $\pi(R, x)$ of discussing return $R$, the parameter $\beta^{\prime}$ captures the value placed on mentioning one's high return experience, versus the appropriateness of doing so. The more tightly bound is the sender's self-esteem or reputation to return performance, the larger is the parameter $\beta^{\prime}$, and hence the stronger is SET, as measured by $\beta$ in the sending function (1) which is proportional to $\beta^{\prime}$.

The constant $\gamma$ in the sending function (1) reflects the conversability of the investment choice. When investment is a more attractive topic for conversation or when conversations are more extensive, as occurs when investors are more sociable, higher $\gamma$ shifts the distribution of $x$ to the right (i.e., an increase in $\tau_{2}$, for given $\tau_{2}-\tau_{1}$, implies higher $\gamma$ ).

\section{B.2 The Receiving Function}

We derive an increasing convex increasing shape for the receiving function as in equation (2) in Section 2.3 from the combination of two effects: greater receiver attention to extreme return 
outcomes, and, conditional upon paying attention, and, owing to the representativeness heuristic, greater persuasiveness of higher return.

The return on a sender or receiver strategy has unknown mean $\mu^{i}, i=s, r$, where $R^{i}=\mu^{i}+\epsilon^{i}$, where for tractability the receiver perceives the distribution of the means as $\mu^{i} \sim N\left(\mu_{0}^{i}, \sigma_{\mu i}^{2}\right)$, $\epsilon^{i} \sim N\left(0, \sigma_{\epsilon i}^{2}\right)$. Assume all RHS random variables are independent.

The receiver is exposed to a realization of $\left(R^{s}, R^{r}\right)$ and to the sender's type. A receiver can, at cost $\sim U\left(0, \bar{c}_{1}\right)$, pay attention, in which case, the receiver learns the direct cost of switching strategies, $c_{2} \sim U\left(\underline{c}_{2}, \bar{c}_{2}\right)$, and optimizes over whether to switch. A non-attending receiver incurs no cost, and never switches. The costs of paying attention and of switching depends on situationspecific circumstances not observed by the econometrician.

We assume that $\underline{c}_{2}<0<\bar{c}_{2}$. The possibility that the 'cost' of switching is negative reflects a possible favorable inference by the receiver about the sender's adoption of the sender's strategy. (It could alternatively reflect conformist preferences.)

The quasi-Bayesian update of $\mu^{i}, i=s, r$ given observed returns

$$
E\left[\mu^{i} \mid R^{i}\right]=\mu_{0}^{i}+\beta^{i}\left(R^{i}-\mu_{0}^{i}\right),
$$

where

$$
\beta^{i}=\frac{\sigma_{\mu i}^{2}}{\sigma_{\mu i}^{2}+\sigma_{\epsilon i}^{2}} .
$$

Here we capture representativeness/overextrapolation taking the form of $\beta_{i}$ being an overestimate of the true relationship, i.e., the receiver regards past returns as being more indicative of future performance than they really are. ${ }^{18}$

We assume for simplicity that an attending receiver switches to the sender's strategy based on whether the difference in updated means $\mu^{s}-\mu^{r}$ exceeds the switch cost $c_{2} \cdot{ }^{19}$

So conditional upon attending and the observed returns, the probability of switching strategies is

$$
P\left(E\left[\mu^{s} \mid R^{s}\right]-E\left[\mu^{r} \mid R^{r}\right]-c_{2} \geq 0\right)=\int_{c_{2}=\underline{c}_{2}}^{\beta^{s} R^{s}-\beta^{r} R^{r}} \frac{d c_{2}}{\bar{c}_{2}-\underline{c}_{2}}=\frac{\beta^{s} R^{s}-\beta^{r} R^{r}-\underline{c}_{2}}{\bar{c}_{2}-\underline{c}_{2}}
$$

when this quantity lies between 0 and 1 , and is at the relevant probability boundary otherwise.

We endogenize the investor's attention heuristic by solving for the optimal decision of whether to pay attention, taking into account $\left(R^{s}, R^{r}\right)$ and what this implies about $\left(\mu^{s}, \mu^{r}\right)$. Owing to cognitive processing constraints, in general we expect this decision to be heuristic. However, a wide set of heuristics are possible, and the result we derive are not driven by bias in this decision. So as a benchmark case that is neutral with respect to bias in the attention decision, we model the attention decision as fully rational, i.e., making full use of $R^{s}, R^{r}$, and $c_{1}$, but not $c_{2}$ which is only

\footnotetext{
${ }^{18}$ Algebraically this could arise from overestimation of $\sigma_{\mu i}^{2}$ and/or underestimation of $\sigma_{\epsilon_{i}}^{2}$. The form of the receiving function that we derive here does not actually require this overextrapolation, but for realistic parameter values $\sigma_{\mu i}^{2} / \sigma_{\epsilon_{i}}^{2}$ would be low, since most of the variance in strategy performance comes from chance rather than differences in means. This would lead to very weak updating, implying a very small slope of the receiving function.

${ }^{19}$ It would not be hard to allow for the effect of risk aversion via an adjustment for the difference in variances of the two strategies. Since prior variances are known, observation reduces posterior variances deterministically, i.e., by the same amount regardless of the signal.
} 
observed after paying attention. ${ }^{20}$ The approach of assuming rationality in attention allocation is also applied in the large literature on rational inattention (Sims 2003), and in other work on limited attention such as Peng and Xiong (2006).

The receiver's attention heuristic is tuned to pay attention if the expected improvement in portfolio expected returns, net of switch costs, and given the observed past returns, exceeds the cost of attention. Let $\mathbf{1}_{E\left[\mu^{s} \mid R^{s}\right]-E\left[\mu^{r} \mid R^{r}\right]-c_{2} \geq 0}$ be an indicator function for the receiver switching to the sender's strategy after attending and observing returns. The receiver attends iff the expected gain exceeds $c_{1}$,

$$
E\left[\left(\mu^{s}-\mu^{r}-c_{2}\right) \mathbf{1}_{E\left[\mu^{s} \mid R^{s}\right]-E\left[\mu^{r} \mid R^{r}\right]-c_{2} \geq 0} \mid R^{s}, R^{r}\right]-c_{1} \geq 0
$$

so substituting out expectations of $\mu$ 's by (B.4), the condition becomes

$$
\frac{\left(\beta^{s} R^{s}-\beta^{r} R^{r}\right)\left(\beta^{s} R^{s}-\beta^{r} R^{r}-\underline{c}_{2}\right)}{\bar{c}_{2}-\underline{c}_{2}}-E\left[c_{2} \mathbf{1}_{\mu^{s}-\mu^{r}-c_{2} \geq 0} \mid R^{s}, R^{r}\right]-c_{1} \geq 0 .
$$

Now the expectation above is

$$
E\left[c_{2} \mathbf{1}_{E\left[\mu^{s} \mid R^{s}\right]-E\left[\mu^{r} \mid R^{r}\right]-c_{2} \geq 0} \mid R^{s}, R^{r}\right]=\frac{\left(\beta^{s} R^{s}-\beta^{r} R^{r}\right)^{2}-\underline{c}_{2}^{2}}{2\left(\bar{c}_{2}-\underline{c}_{2}\right)}
$$

So the receiver attends iff

$$
\frac{\left(\beta^{s} R^{s}-\beta^{r} R^{r}-\underline{c}_{2}\right)^{2}}{2\left(\bar{c}_{2}-\underline{c}_{2}\right)}-c_{1} \geq 0 .
$$

Since $c_{1}$ is uniformly distributed,

$$
P\left(\text { Attend } \mid R^{s}, R^{r}\right)=P\left(c_{1} \leq \frac{\left(\beta^{s} R^{s}-\beta^{r} R^{r}-\underline{c}_{2}\right)^{2}}{2\left(\bar{c}_{2}-\underline{c}_{2}\right)}\right)=\frac{\left(\beta^{s} R^{s}-\beta^{r} R^{r}-\underline{c}_{2}\right)^{2}}{2 \bar{c}_{1}\left(\bar{c}_{2}-\underline{c}_{2}\right)},
$$

which is quadratically increasing in the weighted return difference $\beta^{s} R^{s}-\beta^{r} R^{r}$.

The probability that the receiver switches conditional upon the returns is the product

$$
P\left(\text { Attend } \mid R^{s}, R^{r}\right) P\left(\text { Switch } \mid \text { Attend, } R^{s}, R^{r}\right) \text {. }
$$

The first probability is given in (B.9), and the second in (B.5).

So the probability of switching, i.e., the receiving function, is

$$
r\left(R^{s}, R^{r}\right)=\frac{\left(\beta^{s} R^{s}-\beta^{r} R^{r}-\underline{c}_{2}\right)^{3}}{2\left(\bar{c}_{2}-\underline{c}_{2}\right)^{2} \bar{c}_{1}}
$$

\footnotetext{
${ }^{20}$ Modelling the attention choice as fully rational may seem paradoxical, since it can take more calculations to allocate attention optimally than to simply solve the decision problem at hand. However, again, we view full rationality of the attention decision as merely the most convenient benchmark case. Furthermore, it is not necessary to view our benchmark case as involving full conscious rationality in the attention allocation decision. The calculations needed to allocate attention correctly do not necessarily use cognitive resources at the time of each attentional decision. Attention heuristics can be viewed as having been designed in human evolutionary prehistory to balance the cost of paying attention against the benefits achieving better decision outcomes. Alternatively, the attention mechanism can be viewed as a rule-of-thumb heuristic that the investor has learned through previous experience over the investor's lifetime.
} 
when this quantity lies between 0 and 1 . This is a cubic function of $\beta^{s} R^{s}-\beta^{r} R^{r}$ with all nonnegative coefficients since $\underline{c}_{2} \leq 0$.

A special case of this development is when $\beta^{r}<<\beta^{s}$, in which case the expression approximately simplifies to

$$
r\left(R^{s}\right)=\frac{1}{2\left(\bar{c}_{2}-\underline{c}_{2}\right)^{2} \bar{c}_{1}}\left[\left(\beta^{s} R^{s}\right)^{3}-3 \underline{c}_{2}\left(\beta^{s} R^{s}\right)^{2}+3\left(\underline{c}_{2}\right)^{2} \beta^{s} R^{s}-\left(\underline{c}_{2}\right)^{3}\right]
$$

when this quantity lies between 0 and 1.

A quadratic Taylor approximation leads to a quadratic expression for $r\left(R^{s}, R^{r}\right)$ or, when $\beta^{r}$ small, for $r\left(R^{s}\right)$, as in equation (2) in Section 2.3, where we assume that most of the probability mass of $R$ is in the range where the coefficients of this quadratic approximation are positive, consistent with a convex increasing shape for the receiving function. Specifically, performing this Taylor expansion around $R^{s}=0$ yields the quadratic receiving function coefficients $a=$ $-3 \underline{c}_{2}\left(\beta^{s}\right)^{2} /\left[2\left(\bar{c}_{2}-\underline{c}_{2}\right)^{2} \bar{c}_{1}\right], b=3\left(\underline{c}_{2}\right)^{2} \beta^{s} /\left[2\left(\bar{c}_{2}-\underline{c}_{2}\right)^{2} \bar{c}_{1}\right]$, and $c=-\left(\underline{c}_{2}\right)^{3} /\left[2\left(\bar{c}_{2}-\underline{c}_{2}\right)^{2} \bar{c}_{1}\right]$. By varying the free parameters, any positive vector of values of $(a, b, c)$ is feasible.

\section{Homophily}

Consider a variation of the network model in which there is homophily. Specifically, senders and receivers (or, equivalently links) are no longer randomly selected, but rather the probabilities are tweaked such that the probability that communication (a link) is selected between two agents with the same strategy is relatively higher than the probability that agents with different strategies are selected, by a factor $\chi$.

Specifically, when there is no homophily, the fraction of selected sender-receivers with an active potential sender and a passive potential receiver in a period is $\kappa f_{t}\left(1-f_{t}\right)$. When there is homophily, it is instead $\frac{\kappa}{\chi} f_{t}\left(1-f_{t}\right)$, where $\chi>1$ denotes the degree of homophily. This is also the fraction of passive potential senders and active potential receivers selected.

The transformation rate will then be

$$
E[\Delta f]=\frac{1}{\chi} f(1-f) \kappa \bar{T}+\hat{\lambda}(q-f) .
$$

It is easy to show that compared with the transformation rate in the base model (3), the transformation rate with homophily is lower, and this also carries over to a lower steady state fraction of active investors.

\section{Equilibrium Model}

So far, we have modeled the economy in a partial equilibrium setting with exogenous return distributions for $A$ and $P$, along with informal arguments that when there are more $A$ 's in the investor population, demand for this strategy increases, decreasing future returns. In practice, after extensive inflow of investors into active strategies, we expect the equilibrium price of acquiring strategy positions to rise, reducing expected future returns. So evolution toward $A$ is self-limiting. We now extend the model in a stylized way to capture such equilibrium effects. Without loss of generality, we assume that one agent is chosen in each time period, i.e., that $\kappa=1 / 2 N$. 


\section{The Investment Technology}

We model the supply-side of the economy as a set of short-term investment opportunities with diminishing returns to scale, which implies imperfectly elastic supply. We assume that the output elasticity is lower for investments associated with active than for passive strategies, reflecting the idea that active strategies may be less scalable. For simplicity, we assume that investments associated with $P$ 's are perfectly elastic, whereas investments associated with $A$ 's are not. For example, if $A$ is buying IPO stocks, and if the supply of excellent new business opportunities is limited, then there will be diminishing returns to aggregate investment in $A$. As a special case, the passive investment could, for example, represent a low-risk storage technology.

The one-period returns in this case depend on total active investments, $X$, as

$$
\begin{aligned}
R_{A}\left(N_{A}\right) & =\left(\beta_{A} r+\epsilon_{A}+v\right) \times(\rho X)^{-1 / 2}-v \\
R_{P} & =\beta_{P} r+\epsilon_{P}
\end{aligned}
$$

where the $N_{A}$ is the total number of active investors, $v>0, \rho>0$ are parameters, and $X$ in equilibrium will depend on $N_{A} \cdot{ }^{21}$ Also, $r$ denotes a common component of returns shared by $A$ and $P$ (e.g., the market portfolio), $E[r]=0, \beta_{i}$ is the sensitivity of strategy return to the common return component, $\epsilon_{i}$ is a strategy-specific component, $E\left[\epsilon_{i}\right]=0, i=A, P$. We assume that $r, \epsilon_{A}$ and $\epsilon_{P}$ are independent, with skewness $\gamma_{A}$ and $\gamma_{P}$, respectively, and that the skewness of $r$ is zero.

\section{The Investor Objective}

The objective of investors is to maximize the mean-variance expected utility function

$$
U=E[R]-\left(\frac{\zeta}{2}\right) \operatorname{Var}(R)
$$

where for simplicity we set the risk aversion coefficient $\zeta=1$. The riskfree asset has return $r_{f}$. Here, since we have normalized such that $E[r]=E\left[\epsilon_{A}\right]=E\left[\epsilon_{P}\right]=0$, we assume that $r_{f}<0$. The negative riskfree rate could, for example, represent a storage technology with some depreciation. This assumption could easily be modified, at the cost of greater algebraic complexity, by allowing for additional intercept components of returns in (D.1) and (D.2).

By assumption, the P's maximize expected utility of investing in a portfolio consisting of a risky investment alternative that is available to $P$ investors, and the riskfree asset. Similarly, $A$ 's optimize a portfolio of a risky investment alternative that is available to $A$ investors, and the riskfree asset. Investors optimize rationally, but do not consider including both passive and active assets in their portfolios at the same time. ${ }^{22}$ In equilibrium, active investors' total demand is $X$, where they optimize expected utility given the return distribution in (D.1).

\footnotetext{
${ }^{21}$ The return specification in (D.1) corresponds to a concave production function where input $X$ leads to stochastic production $\left(\beta_{A} r+\epsilon_{A}+v\right) \times\left(\frac{X}{\rho}\right)^{1 / 2}-v X$. The parameters are such that a higher $\rho$ is associated with a lower expected output, and a higher $v$ corresponds to a more concave production function.

${ }^{22}$ Our assumption of an increasing receiving function was based on the idea that investors overextrapolate reports about past return performance. This suggests that investors will have overoptimistic expectations about the strategies they have been persuaded to adopt. It would be easy to incorporate such overestimation
} 


\section{Joint Determination of Strategy Popularity and Asset Returns}

In this specification, the return penalty, $D_{N_{A}}$, depends on $N_{A}$, the number of $A$ 's. We choose a specific value for the $\rho$ parameter,

$$
\rho=\frac{2\left(\beta_{A}^{2} \sigma_{r}^{2}+\sigma_{A}^{2}\right)}{N\left|r_{f}\right|},
$$

which in equilibrium implies an initial return penalty of zero, $D_{N / 2}=0$. Here, we have assumed that $f_{0}=\frac{1}{2}$, i.e., that half of the population initially invests in each strategy. Moreover, we assume that $q=\frac{1}{2}$, so that new investors also invests equally in the two strategies.

The case of a zero return penalty to active investing is a simple benchmark case that is useful for identifying what influences the spread of competing investment strategies when the obvious effect of expected return differences is neutralized. It follows from the dependence here of equilibrium return on the number of $A$ 's that the transformation probability also depends on $N_{A}$,

$$
\bar{T}_{N_{A}}^{A}=E\left[T_{A}\left(R_{A}\left(N_{A}\right)\right)\right]
$$

The following proposition provides conditions under which the results from Sections 3.2-3.3 generalize to the equilibrium setting.

Proposition 7 Under the parameter restrictions that $\left|r_{f}\right|$ is small, $\kappa \geq\left|r_{f}\right|, \gamma_{P}=0, \gamma_{A} \geq 0$, and

$$
\begin{aligned}
\beta_{A} & >2 \beta_{P} \\
\sigma_{A} & >2 \sigma_{P},
\end{aligned}
$$

Proposition 2, Proposition 3:2-3:3, and Proposition 4 continue to hold in equilibrium. Moreover, the returns an investor is expected to receive from active investments is nonpositive and strictly decreasing over time.

In equilibrium, active investments thus dominate, and the return penalty is positive, in line with the core results of the partial equilibrium model. Intuitively, transmission bias causes $A$ to spread, putting a downward pressure on the returns to the $A$ strategy, and thereby inducing a return penalty to active investing. In other words, owing to transmission bias, $A$ investing persists despite needing to climb uphill against a return penalty.

The sufficient condition on $\sigma_{A}$ is stricter in the equilibrium setting, as seen by the extra factor 2 in (D.6). This factor arises because the restriction $\bar{T}_{N_{A}}^{A}$ depends on the number of active investors, $N_{A}$, and $\bar{T}_{N_{A}}^{A}>\bar{T}_{N_{A}}^{P}$ needs to be satisfied for all $1 \leq N_{A} \leq N$. Of course, this is just a sufficient condition.

The only result from Section 3.2 that does not extend to the equilibrium setting is Proposition $3: 1$, the comparative static with respect to the return penalty. Such comparative statics are not well defined in the equilibrium model since the return penalty is endogenous.

into the investor's mean-variance portfolio optimization here, but doing so would not affect the general nature of our conclusions. These are driven by the fact that in our specification, an increase in the fraction of $A$ 's drives down the equilibrium expected return of this strategy. So for simplicity we assume rational mean-variance optimization. 


\section{E Trading Volume}

If we interpret $A$ as active trading in the market for individual stocks, with a preponderance of long positions, then a high market return implies high average returns to $A$ 's. Proposition 1 therefore suggests that when the stock market rises, volume of trade in individual stocks increases. This implication is consistent with episodes such as the rise of day trading, investment clubs, and stock market chat rooms during the millennial internet boom, and with evidence from 46 countries including the U.S. that investors trade more when the stock market has performed well (Statman, Thorley, and Vorkink 2006; Griffin, Nardari, and Stulz 2007). We next study trading volume in the equilibrium model, to verify that evolution toward $A$ is associated with high trading volume.

The total demand of $N_{A}$ active investors, given a risky investment opportunity with expected return $E\left[R_{A}\right]$ and return variance $\operatorname{Var}\left(R_{A}\right)$ is $X=N_{A} \frac{E\left[R_{A}\right]-r_{f}}{\operatorname{Var}\left(R_{A}\right)}$, and market clearance, by (D.1), leads to

$$
X=\frac{\rho \kappa^{2} N_{A}^{2}}{\left(\rho v N_{A}-\rho N_{A}\left|r_{f}\right|+\left(\beta_{A}^{2} \sigma_{r}^{2}+\sigma_{A}^{2}\right)\right)^{2}} .
$$

When an investor switches from $P$ to $A$, he liquidates his passive portfolio position of

$$
\frac{\left|r_{f}\right|}{\sigma_{P}^{2}}
$$

the number of active investors increases from $N_{A}$ to $N_{A}+1$, and he invests

$$
\frac{1}{N_{A}+1} X_{N_{A}+1}
$$

in the active investment. Here, in equilibrium,

$$
X_{N_{A}}=\frac{2 v^{2} N N_{A}^{2}\left|r_{f}\right|}{\left(2 N_{A}\left(v-\left|r_{f}\right|\right)+N\left|r_{f}\right|\right)^{2}\left(\beta_{A}^{2} \sigma_{r}^{2}+\sigma_{A}^{2}\right)} .
$$

Moreover, the $N_{A}$ investors that are already active rebalance from a total position of $X_{N_{A}}$ to $\frac{N_{A}}{N_{A}+1} X_{N_{A}+1}$. The total trading volume is thus: $\frac{\left|r_{f}\right|}{\sigma_{P}^{2}}+Z_{N_{A}}$, where

$$
Z_{N_{A}} \stackrel{\text { def }}{=} \frac{1}{N_{A}+1} X_{N_{A}+1}+N_{A}\left|\frac{X_{N_{A}}}{N_{A}}-\frac{X_{N_{A}+1}}{N_{A}+1}\right| \text {. }
$$

It is easy to verify that when $v+r_{f} \approx 0$, i.e., when $\left|r_{f}\right|$ is of similar size as $v$, then $\frac{X_{n}}{n}$ is increasing in $n$, and therefore

$$
Z_{N_{A}}=X_{N_{A}+1}-X_{N_{A}}
$$

Moreover, when $v=-r_{f}$,

$$
Z_{N_{A}}=\frac{2 v}{N\left(\beta_{A}^{2} \sigma_{r}^{2}+\sigma_{A}^{2}\right)}\left(1+2 N_{A}\right)
$$

which is strictly increasing in $N_{A}$. Therefore, by continuity, for $v+r_{f} \approx 0$, total trading volume, is also strictly increasing in $N_{A}$.

An identical argument applies to the situation when an investor switches from $A$ to $P$. Specifically, if there are initially $N_{A}+1$ investors, and an investor switches from $A$ to $P$, that investor invests $\frac{\left|r_{f}\right|}{\sigma_{P}^{2}}$ in the passive strategy, sells $\frac{1}{N_{A+1}} X_{N_{A+1}}$ in the active investment, whereas the other $N_{A}$ investors in total rebalance from $N_{A} \frac{X_{N_{A+1}}}{N_{A+1}}$ to $X_{N_{A}}$. Again, the total trading volume is described by $\frac{\left|r_{f}\right|}{\sigma_{P}^{2}}+Z_{N_{A}}$. 